\title{
Studies of the Formation of Smoke Phenols*
}

\author{
by \\ Alexander J. Dyakonov, Rana T. Walker, Christine A. Brown, Florian R. Perini, D. Scott Passer, \\ Jun Guan, and Edward A. Robinson \\ A. W. Spears Research Center, Lorillard Tobacco Co., 420 English St., Greensboro NC 27420, USA
}

\section{SUMMARY}

Processes involving or forming phenols during combustion of tobacco were studied by differential scanning calorimetry (DSC), thermogravimetry (TG), mass-spectrometry (MS), X-band electron spin resonance (ESR), and thermocouple (TCT) and infrared thermography (IRT) methods. Thermochemical properties of polyhydroxybenzenes, polynuclear aromatic hydrocarbons (PAHs), and carbohydrates were investigated both individually and when the compounds were embedded in combustible or non-combustible matrices; the compounds were studied in an $\mathrm{O}_{2} / \mathrm{He}$ atmosphere at temperatures up to $800{ }^{\circ} \mathrm{C}$, with a heating rate up to $60{ }^{\circ} \mathrm{C} / \mathrm{min}$. ESR of the mainstream smoke 'tar' was performed at temperatures down to $-253{ }^{\circ} \mathrm{C}$. The radicals found differed in their magnetic behavior depending on the material studied; this difference was attributed to the presence of relatively unstable isolated semiquinone and/or PAH-type molecules and the more stable quinone-hydroquinone-semiquinone redox complex.

Phenols themselves were found to affect combustion by radical scavenging and initiation. Added carbohydrates introduced diffusion limitations to oxygen. They also affected the combustion temperatures and could intensify the formation of phenols via quinone. Oxidation of PAHs was investigated and enthalpies were determined. These enthalpies decreased from benzo $[a]$ pyrene $(\mathrm{B} a \mathrm{P})$ to anthracene, naphthalene and phenanthrene. [Beitr. Tabakforsch. Int. 23 (2008) 68-84]

\section{ZUSAMMENFASSUNG}

Prozesse, bei denen Phenole beteiligt sind oder während der Verbrennung von Tabak gebildet werden, wurden mit Hilfe der Differentialthermokalorimetrie (DSC), Thermogravimetrie (TG), Massenspektrometrie (MS), Elektronenspinresonanz-Scanning (EPR), sowie Thermocouple-
(TCT) und Infrarotthermographie (IRT) untersucht. Die thermochemischen Eigenschaften der Polyhydroxybenzole, polyzyklischen aromatischen Kohlenwasserstoffe (PAHs) und Kohlehydrate wurden sowohl einzeln als auch in Verbindung mit brennbaren und nicht brennbaren Matrizes analysiert; die Verbindungen wurden in einer $\mathrm{O}_{2} / \mathrm{He}$ Atmosphäre bei Temperaturen bis $\mathrm{zu} 800{ }^{\circ} \mathrm{C}$ und einer Temperatursteigerung von bis $\mathrm{zu} 60{ }^{\circ} \mathrm{C} / \mathrm{min}$ untersucht. Die ESR-Messungen des Kondensats im Hauptstromrauch wurde bei Temperaturen bis zu $-253{ }^{\circ} \mathrm{C}$ durchgeführt. Die gefundenen Radikale unterschieden sich in ihrem magnetischen Verhalten je nach untersuchtem Material, dieser Unterschied wurde dem Vorliegen relativ instabiler isolierter Semiquinone und/oder PAH-ähnlicher Moleküle und dem stabileren Quinon-Hydroquinone-Semiquinone Redoxkomplex zugeschrieben.

Es wurde festgestellt, dass Phenole Einfluss auf die Verbrennung durch Einfangen und Initiation der Radikale ausüben. Hinzugefügte Kohlehydrate begrenzten die Diffusion des Sauerstoffs. Sie übten ebenfalls einen Einfluss auf die Verbrennungstemperaturen aus und verstärkten die Bildung der Phenole aus dem Quinon. Die Oxidation der PAHs wurde untersucht und die Enthalpien wurden bestimmt. Die Enthalpien verringerten sich vom Benzo $[a]$ pyren $(\mathrm{B} a \mathrm{P})$ zum Anthracen, Naphtalen und Phenanthren. [Beitr. Tabakforsch. Int. 23 (2008) 68-84]

\section{RESUME}

Des processus dans lesquels les phénols participent ou sont formés pendant la combustion du tabac, ont été examinés avec la calorimétrie par scannage différentiel (DCS), thermogravimétrie (TG), spectrométrie de masse (MS), résonance de spin d'électron à bande X (ESR) et par des méthodes à thermocouple (TCT) et thermographie à infrarouge. Les propriétés thermochimiques des polyhydroxy benzènes, des hydrocarbures polynucléaires aromatiques et 
les hydrates de carbone ont été analysées séparément et incorporées dans des matrices combustibles et non combustibles, dans une atmosphère à oxygène et hélium sous des températures allant jusqu'à $800{ }^{\circ} \mathrm{C}$ avec un taux de chauffage de $60{ }^{\circ} \mathrm{C} / \mathrm{min}$. L'analyse ES du goudron présent dans la fumée principale a été réalisée avec des températures jusqu'à $-253{ }^{\circ} \mathrm{C}$. Les radicaux trouvés diffèrent dans leur comportement magnétique en fonction de la matière examinée; cette différence a été attribuée à la présence de semiquinones isolés relativement instables,des molécules de types PAH et des complexes redox de quinone-hydroquinone-semiquinone plus stables.

Il a été observé que les phénols eux-mêmes affectent la combustion par piégeage et initiation. L'apport des hydrates de carbone conduit à des limitations de la diffusion d'oxygène. Ils affectent également les températures de combustion et pourraient intensifier la formation des phénols par la quinone. L'oxydation des PAHs a été examinée et les enthalpies ont été déterminées. Ces enthalpies diminue du benzo $[a]$ pyrène $(\mathrm{B} a \mathrm{P})$ jusqu'à l'anthracène, naphthalène et phénanthrène. [Beitr. Tabakforsch. Int. 23 (2008) 68-84]

\section{INTRODUCTION}

Natural fuels, such as wood, tobacco and peat are rich in phenols. During combustion and pyrolysis, these phenols can decompose, distill, or produce a variety of new compounds, which may be damaging to the environment and human health. For example, SCHLOTZHAUER et al. (1) considered catechol, which can be formed during combustion, to be a co-carcinogen in tobacco smoke. Usually the problem of abatement of these compounds can be solved by constructing a more efficient combustion device. However, in the case of tobacco smoldering, phenolic compounds are an integral part of a matrix containing flavor materials generated during cigarette smoking. Attempts to selectively remove phenols from smoke in the filter were moderately successful only in the case of the most volatile compound - phenol, as SPEARS $(2,3)$ showed 40 years ago. Therefore, controlling combustion probably remains the only efficient method to minimize the yield of hydroxybenzenes from cigarette. Knowledge about the reaction mechanisms in which phenolic compounds are involved is a necessary prerequisite for their abatement from smoke.

\section{Sources of phenols}

The concentration of phenols in smoke is generally determined by rates of their formation and consumption. Depending on the conditions, these reactions may include formation from naturally occurring polyhydroxybenzenes, from aromatic hydrocarbons, and from carbohydrates as shown by BELL et al. (4) in 1965. Other types of organic compounds, such as sterols (5), may also participate.

The formation of phenols from naturally occurring phenolics (primarily chlorogenic acid and lignin) in fuels was considered by BASSILAKIS et al. (6) and BALIGA et al. (7). This release may be represented by the following processes:

$$
\begin{aligned}
\text { chlorogenic acid } & \rightarrow \text { lignin }(8) ; \\
\text { chlorogenic acid } & \rightarrow \text { char }(9) ; \\
\text { chlorogenic acid } & \rightarrow \text { phenols (1); } \\
\text { lignin } & \rightarrow \text { phenols (10); }
\end{aligned}
$$

where chlorogenic acid represents phenolic esters, lignin represents phenolic ethers biosynthesized in the plants (11), and phenolics include phenol, catechol, resorcinol and hydroquinone derivatives. In living plants chlorogenic acid, a phenolic metabolite, directly participates in lignin biosynthesis (8).

SCHLOTZHAUER et al. (1) and SHARMA et al. (12) suggested that the primary source of phenols in smoke is chlorogenic acid. They also found that dark cured tobacco has less chlorogenic acid and produces fewer phenols when combusted. BOKELMAN and RAYAN (13) showed that lignin concentration did not vary greatly from one type of leaf to another. Their conclusion was that chlorogenic acid content is one of the dominant factors in determining the amount of phenols in smoke.

The primarily carbohydrate, pectin, contains phenolic structures, such as the guaiacol groups in dehydrodiferulic acid (14) which can be cleaved to directly produce phenols.

Lignin might also contribute to the formation of phenols, although cleavage of this larger molecule may be slow and requires temperatures as high as $300{ }^{\circ} \mathrm{C}(15)$. The plant's growing temperature, light spectrum exposure, and duration of illumination, along with the tobacco curing conditions, all impact the formation of phenolics $(16,17)$. These effects have been examined by studying enzyme catalysis that converts phenolic acids to lignin in plant leaves $(14,16)$. In these studies, naturally occurring phenolics were found to be important for the plant's normal growth and their removal $(18,19)$ could induce dramatic changes in the plant.

Investigation of the decomposition of phenolics is necessary for the development of a kinetic model for control of phenols yield. However, in the case of phenolic-containing fuel, this investigation is complicated by two major factors. First, the most abundant polyphenol, lignin, is a natural polymeric component in each fuel. Although the concentration of lignin in the fuel can be varied, either extraction or addition of lignin will change its structure and create additional experimental artifacts $(4,20,21)$. The second factor is the slow temperature ramping rate, which must be used when studying the partial processes that comprise combustion. The work presented herein addresses the first factor. We have attempted to determine whether lignins from different plant sources provide similar thermal decomposition profiles.

Unlike the polymeric lignins, chlorogenic acid and its counterparts, caffeic and quinic acids are individual compounds. Concentrations of these compounds can be varied in the fuel in order to investigate the kinetic features of their decomposition to phenols. However, even in this case, an accurate experiment does not seem to be possible, because of inevitable differences that are introduced to the structure of the fuel matrix and to the distribution of an additive by extraction and doping.

The pathways for formation of phenolics from carbohydrates can be very different from those for aromatic structures. According to GAMBORG (22), cyclohexanedien 
structures can be formed from six-membered ring carbohydrates at relatively low temperatures, whereas the quinone structure is a precursor to phenols. The plant chemistry of a relatively abundant carbohydrate, quinic acid and its dehydrated form, shikimic acid, has been investigated in numerous papers over 50 years $(22,23)$. The results of these studies also imply that quinones in smoke are not necessarily the products of oxidation of the corresponding dihydroxybenzenes. The quinones formed at low temperature from sugars may subsequently interact with phenols that have different formation routes, e.g., from polyphenols, to produce redox couples of semi-quinone radicalcarrying species. They can also participate in low temperature combustion mechanisms.

The network of reactions involving phenols during combustion may also include such processes as the formation of PAHs from phenolic compounds via cyclopentadienyl radicals $(9,24)$, complete catalytic cracking to the gaseous products (25), and PAH oxidation back to phenolic compounds and other oxygen-containing molecules $(10,26)$. Formation of PAHs and char from carbohydrates, including pectin, and from chlorogenic acid was investigated by MCGRAPH et al. (27) and by SHARMA et al. (9). These studies $(10,27)$ provide important information on oxidative mechanisms of phenols formation and the role of carbohydrates in the process. The process of oxidation of PAHs to phenols has not yet been investigated under combustion conditions.

We studied three phenolic precursor types: carbohydrates, polyhydroxybenzenes, and polynuclear aromatic hydrocarbons (PAHs). While some phenols in smoke are chemically formed from carbohydrates, the polyhydroxybenzenes are phenols themselves. Therefore, in addition to the formation of phenols, we considered the delivery in smoke of phenols cleaved from polyhydroxybenzenes. The third possible precursor type, the PAHs, has to undergo oxidation and cleavage to produce phenols. During the course of this work, PAHs showed quite high resistance to oxidation, making them the least probable contributor to smoke phenols.

\section{Reactions of phenols}

The simplest individual phenol, $\mathrm{C}_{6} \mathrm{H}_{5} \mathrm{OH}$, has been found to be a precursor to a variety of di- and poly-condensation products, many of which are radicals. The reaction pathways proceed via phenoxy or cyclopentadienyl radicals and produce phenoxy-phenols, biphenyls, dibenzofurans, dibenzodioxins and aromatic hydrocarbons (10). In the presence of chlorine, a natural fuel impurity, this reaction network appears to become more complex (28) and produce chlorinated dioxins, compounds of major environmental concern (29). In addition, participation of inorganic compounds, the concentration of which is usually high in ash, is influential in the yield of dioxins (30).

Radical-driven reactions of dihydroxybenzenes have been explored for over 40 years, since their identification in cigarette smoke condensate (31). The initial model suggested that the 'tar' radical was a delocalized spin in a fused PAH. PRYOR et al. (32) found similarities between smoke particulate phase radicals and the free radicals found in melanin, which is a naturally occurring polymeric quinone and hydroquinone. The phenolic-containing tobaccos did not generate radicals if volatile compounds were only distilled, but not oxidized. The presence and nature of radicals in, for example, tea leaves even before combustion (33), have also been associated with reactive oxygen species.

Additionally, the non-paramagnetic behavior of the smoke 'tar' at low temperatures, assessed by electron spin resonance (ESR) measurements, indicated that a redox system with a thermal equilibrium could be involved. This equilibrium reaction caused a diamagnetic ground state and a paramagnetic excited state. This system was investigated by PRYOR et al. (34) and was attributed to quinone/hydroquinone present in the 'tar' matrix.

The quinone/semiquinone/hydroquinone species ( $\mathrm{Q}+$ $\mathrm{QH}_{2}$ ) may participate in the major oxidation reactions as outlined below (34). Atmospheric $\mathrm{O}_{2}$ is reduced by semiquinone (HQ•) to form superoxide, which then disproportionates to form hydrogen peroxide. $\mathrm{H}_{2} \mathrm{O}_{2}$ is an active oxidant known to react with metals, in particular iron (II), which is present in tobacco, producing reactive hydroxyl radicals. In addition, superoxide $\left(\mathrm{O}_{2}^{-}\right)$also reacts with nitrogen oxide $(\mathrm{NO})$, producing peroxynitrite:

$$
\begin{array}{ll}
\mathrm{Q}+\mathrm{QH}_{2} & \leftrightarrow 2 \mathrm{HQ} \bullet \\
\mathrm{HQ} \bullet+\mathrm{O}_{2} & \rightarrow \mathrm{Q}+\mathrm{O}_{2}^{-} \bullet \\
2 \mathrm{O}_{2}^{-}+2 \mathrm{H}^{+} \rightarrow \mathrm{O}_{2}+\mathrm{H}_{2} \mathrm{O}_{2} \\
\mathrm{H}_{2} \mathrm{O}_{2}+\mathrm{Fe}(\mathrm{II}) \rightarrow \mathrm{HO} \bullet+\mathrm{OH}^{-}+\mathrm{Fe}(\mathrm{III}) \\
\mathrm{O}_{2}^{-}+\mathrm{NO} \bullet \rightarrow{\mathrm{ON}-\mathrm{OO}^{-}}^{-}
\end{array}
$$

The formed radical species have the potential to initiate new oxidation chains. Therefore, phenols and their derivatives can both inhibit and initiate radical-driven processes depending upon the combustion conditions.

The possibility of $\mathrm{O}_{2}$ uptake in natural fuels may lead to accumulation of hydroperoxides and participation of phenols in this process. MORSY and KHALED [35] reported a sharp ESR signal (a.u.) that is characteristic of semiquinone radicals in plant leaves. This signal increased as the material was heated and that was interpreted to be evidence of $\mathrm{O}_{2}$ interacting with phenols in the leaves.

The concentration of radicals in the smoke particulate phase was found to be about two orders of magnitude lower than in the vapor phase (36). It is possible that not all particulate phase radicals are formed in the combustion zone, with a significant portion of the radicals formed as secondary species in smoke by interaction of the gas phase radicals with phenols. Semiquinone radicals have the potential to form superoxide, which might be stabilized in the particulate phase.

\section{EXPERIMENTAL}

\section{Preparation of additive-containing fuel samples}

Experiments were performed with polyhydroxybenzenes, polynuclear aromatic hydrocarbons (PAHs), and carbohydrates. These groups were represented by lignins, pectin, glucose, phenol, hydroquinone, resorcinol, catechol, guaiacol, chlorogenic acid, caffeic acid, quinic acid, rutin, quercetin, naphthalene, anthracene, phenanthrene and benzo $[a]$ pyrene, which are naturally present in tobacco or form during combustion. Information on them is provided in Tables 1 and 2 . 
Table 1. Characteristics of the compounds and materials used

\begin{tabular}{|c|c|c|c|}
\hline Material & Description and CAS number ${ }^{a}$ & Received from & $\%$ in fuel or function \\
\hline $\begin{array}{l}\text { Lignin } \\
\text { (A) alkali } \\
\text { (H) hydrolytic } \\
\text { (S) organosolv }\end{array}$ & $\begin{array}{c}\text { Polyphenolics: } \\
8068-05-1 \\
8072-93-3 \\
8068-03-9\end{array}$ & Aldrich & 8 \\
\hline Rutin & 153-18-4 & Acros & 8 \\
\hline Chlorogenic acid & $327-97-9$ & Sigma & 8,15 \\
\hline Quinic acid & $77-95-2$ & Aldrich & 8 \\
\hline Pectin & $9000-69-5$ & Sigma & 8 \\
\hline Quercetin & $117-39-5$ & Fluka & 8 \\
\hline Glucose & $8029-43-4$ & Mallinckroft & 15 \\
\hline Caffeic acid & $331-39-5$ & Acros & 8 \\
\hline TB (tobacco blend) & code $2 \mathrm{R} 4 \mathrm{~F}$ & Univ. Kentucky & 77,69 \\
\hline Guar gum & $9000-30-0$ & TIC Gums, Inc. & 13 \\
\hline Solka-Floc® 1016 grade & $9004-34-6$ & Int. Fiber Corp. & 87,79 \\
\hline Phenol & $108-95-2$ & Sigma & 8 \\
\hline Resorcinol & $108-46-3$ & Sigma & 8 \\
\hline Hydroquinone & $123-31-9$ & Sigma & 8 \\
\hline Catechol & $120-80-9$ & Sigma & 8 \\
\hline Guaiacol & $90-05-1$ & Mother Murphy & 8 \\
\hline Naphthalene & $91-20-3$ & Aldrich & 8 \\
\hline Anthracene & $120-12-7$ & Aldrich & 8 \\
\hline Phenanthrene & $85-01-8$ & Aldrich & 8 \\
\hline Benzo[a]pyrene & $50-32-8$ & Aldrich & 8 \\
\hline $\mathrm{SiO}_{2}$ ultra pure & 35-70 mesh & SiliCycle & tar trap - ESR \\
\hline $\mathrm{KHCO}_{3} / \mathrm{KCl}=1 / 1$ & in $2 \mathrm{R} 4 \mathrm{~F}$ tobacco & Aldrich & 6 \\
\hline $\mathrm{Al}_{2} \mathrm{O}_{3}$ Brockmann & 150 mesh & Aldrich & PAH support \\
\hline
\end{tabular}

${ }^{a}$ CAS $=$ Chemical Abstracts Service Registry Number

Table 2. Structures of the compounds used as additives; lignins and pectin are complex materials representing phenolics and carbohydrates, respectively

\begin{tabular}{|c|c|c|}
\hline Rutin & $\begin{array}{l}\text { Carbohydrates (pectin, } \\
\text { glucose and cellulose): } \\
{\left[\left(\mathrm{C}_{6} \mathrm{H}_{10} \mathrm{O}_{5}\right)_{\mathrm{p}}-\left(\mathrm{C}_{7} \mathrm{H}_{12} \mathrm{O}_{5}\right)_{\mathrm{m}}\right]_{\mathrm{n}}}\end{array}$ & $\begin{array}{l}\text { Phenolics (phenol, } \\
\text { catechol, resorcinol, hydroquinone): } \\
\mathrm{C}_{6} \mathrm{H}_{6-\mathrm{n}}(\mathrm{OH})_{\mathrm{n}}\end{array}$ \\
\hline $\begin{array}{l}\text { PAHs (naphthalene, } \\
\text { anthracene, phenanthrene, } \\
\text { BaP): } \\
\qquad C_{n} H_{(n / 3)+4}\end{array}$ & $\begin{array}{l}\text { Guaiacol } \\
\mathrm{C}_{6} \mathrm{H}_{4}(\mathrm{OH})\left(\mathrm{OCH}_{3}\right)\end{array}$ & Caffeic acid \\
\hline Chlorogenic acid & Quinic acid & Quercetin \\
\hline
\end{tabular}

In a typical experiment, a cellulose sheet (CS) was prepared from $45 \mathrm{~g}$ of a dry mixture consisting of 13\% guar gum, $79 \%$ cellulose powder and $8 \%$ additive. For the tobacco blend (TB)-based samples, a mixture consisting of $69 \%$ ground 2R4F cigarette tobacco blend, 10\% cellulose, 13\% guar gum and $8 \%$ additive was prepared. Approximately $600 \mathrm{~mL}$ tap water $(\mathrm{pH} \sim 6.75)$ was added and the resulting solution or suspension was mixed for about $3 \mathrm{~min}$ in a Waring (New Hartford, CT) laboratory blender. Routine analysis of the tap water was performed with a Dionex $4500 \mathrm{i}$ ion chromatograph, showing a nitrate ion concentration of approximately $160 \mu \mathrm{g} / \mathrm{L}$ and no nitrite and phosphate ions present. A 2-mm thick layer of partially gelled suspension of about $0.3 \mathrm{~m} \times 1 \mathrm{~m}$ size was cast onto a rectangular Tefloncoated glass plate using a film spreader, and the sheet was allowed to air dry at room temperature. The sheets were then conditioned at $75{ }^{\circ} \mathrm{C}$ and $60 \%$ relative humidity, cut into 1$\mathrm{mm}$ wide strips, and stored in plastic jars. 


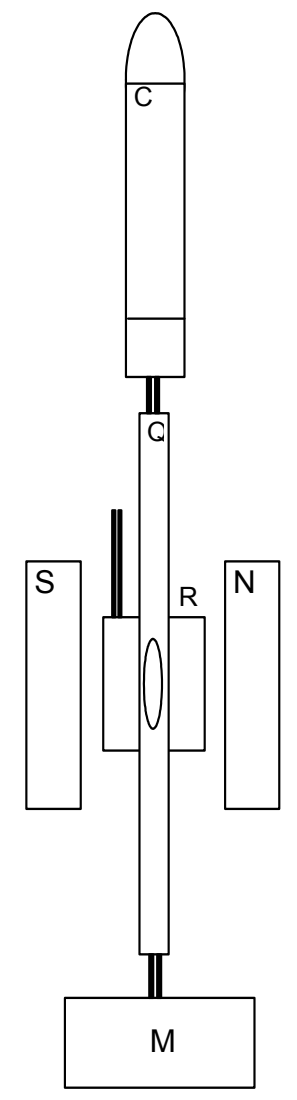

Figure 1. In-situ measurements of TPM, accumulated on silica gel, positioned in the center of the sample tube $(Q)$ in resonator (R) of ESR spectrometer magnet (S-N); Cigarette (C) is smoked by smoking machine (M).

Comparison samples were prepared in the same manner with no additive present. Therefore, CS contained $87 \%$ cellulose and $13 \%$ guar gum; TB contained $77 \%$ tobacco, $13 \%$ guar gum and $10 \%$ cellulose. A sample, which is known to generate more fragmented tobacco compounds (including phenolics), was prepared by adding $6 \%$ of $1: 1$ mixture of $\mathrm{KHCO}_{3}$ and $\mathrm{KCl}$ to $\mathrm{TB}$ by spraying an aqueous solution of these salts and air-drying the resulting material at ambient temperature.

The experimental fuels were investigated in the form of loose particles by differential scanning calorimetry/thermogravimetry (DSC/TG). For the thermocouple thermography (TCT) and infrared thermography (IRT) temperature measurements and for ESR experiments, experimental cigarettes were prepared. For this purpose, one gram of TB- or CS-based fuel was packed into an $85-\mathrm{mm}$, Premier Supermatic (Clinton Tube (USA) Inc., Plattsburgh, NY) filter-tipped cigarette tube with no air ventilation.

Samples with polynuclear aromatic hydrocarbons were prepared from each $\mathrm{PAH}$ and $\mathrm{Al}_{2} \mathrm{O}_{3}$. A 100-mg sample of each $\mathrm{PAH}$ (naphthalene, anthracene, $\mathrm{B} a \mathrm{P}$, and phenanthrene) was dissolved in approximately $5 \mathrm{~mL}$ of cyclohexane. One gram of $\mathrm{Al}_{2} \mathrm{O}_{3}$ was heated for $24 \mathrm{~h}$ at $400{ }^{\circ} \mathrm{C}$ in air, cooled and added into the solution to make $10 \%$ $\mathrm{PAH}$ on alumina as the final product. The bottles were capped, shaken for a few minutes and then uncapped and placed under a fume hood for half a day, where the solvent evaporated. White powders of alumina-supported naphthalene, anthracene, and phenanthrene and a light green $\mathrm{B} a \mathrm{P} /$ alumina were prepared.

\section{Experimental techniques}

For simultaneous thermo-gravimetry with differential scanning calorimetry, a TG-DSC 111 (Setaram, Caluire, France) was coupled with a ThermoStar (Pfeiffer, Asslar, Germany) mass-spectrometer (MS). A $39 \mathrm{~mL} / \mathrm{min}$ flow of $9 \% \mathrm{O}_{2}$ in $\mathrm{He}$ was passed through the reactor, where from 5 to $50 \mathrm{mg}$ of sample was placed in a platinum basket. The reactor temperature was programmed linearly from 30 to $800{ }^{\circ} \mathrm{C}$ at a rate from 5 to $60{ }^{\circ} \mathrm{C} / \mathrm{min}$. The MS was set to scan the $\mathrm{m} / \mathrm{e}$ values from 1 to 200 at a rate of 1 unit per second.

An X-band EMX ESR spectrometer from Bruker Biospin (Billerica, MA) monitored free radicals in the combustion 'tar', which was collected on silica gel as shown in Figure 1. A 1-mm plug of high-purity quartz wool was inserted into a 4-mm diameter Clear Fused Quartz flow-through tube from Wilmad LabGlass (Buena, NJ) to support approximately $100 \mathrm{mg}$ of ultra pure silica gel (SiliCycle, Quebec, Canada). This silica gel (35-70 mesh, $400 \mathrm{~m}^{2} / \mathrm{g}$ ) was selected for ESR measurements because it showed no signal under the measurement conditions. The sample tube was positioned so that the silica gel plug was in the center of the ESR measuring cavity. One cigarette was smoked through an ESR tube under Federal Trade Commission (FTC) conditions (2-second puffs of $35 \mathrm{~mL}$ at $1 \mathrm{~min}$ interpuff period); the cigarette was positioned vertically, firecone facing up. An ESR spectrum was recorded for approximately $20 \mathrm{~s}$ at room temperature within a minute after each puff. Alternatively, the 'tar' on silica, collected from one cigarette, was transferred to a tube, the tube sealed, and ESR spectra were measured at 0.1 tor and temperatures from -253 to $25{ }^{\circ} \mathrm{C}$, with no flow passing through the sample. A typical signal was a broad line of about $7 \mathrm{G}$, centered at approximately $3,350 \mathrm{G}$.

IRT was employed to monitor the temperature profiles of the burning fuel surface. The SC3000 camera with ThermaCAM Researcher 2002 software from FLIR Systems (Boston, MA) was used. It had a high resolution Quantum Well infrared detector, capable of measuring temperatures from -20 to $1500{ }^{\circ} \mathrm{C}$ with a resolution of $320 \times 240$ pixels, sensitivity of $0.03{ }^{\circ} \mathrm{C}$ at room temperature and recording rate up to 300 images per second of 14 bit data. The cigarette was positioned in a horizontal plane with the camera, about $20 \mathrm{~cm}$ from it, and smoked under FTC conditions. The maximum temperatures on the surface of the firecone were recorded during two seconds of puff and averaged by the software. A cigarette coal emittance of 0.98 as found by BAKER (37) was used.

TCT was used to monitor the temperatures in the center of the free burning cigarette. Data from 0.1-mm diameter Ktype thermocouples were acquired via an OMB-DAQ-55 (Omega Engineering, Stamford, CT) recording system. Typically, four thermocouples were inserted into the center of the cigarette, positioned $1 \mathrm{~cm}$ apart. Under free smoldering conditions, the gas-phase and solid-phase temperatures are in equilibrium. Hence the thermocouple tip measured the temperature of the nearest solid. 


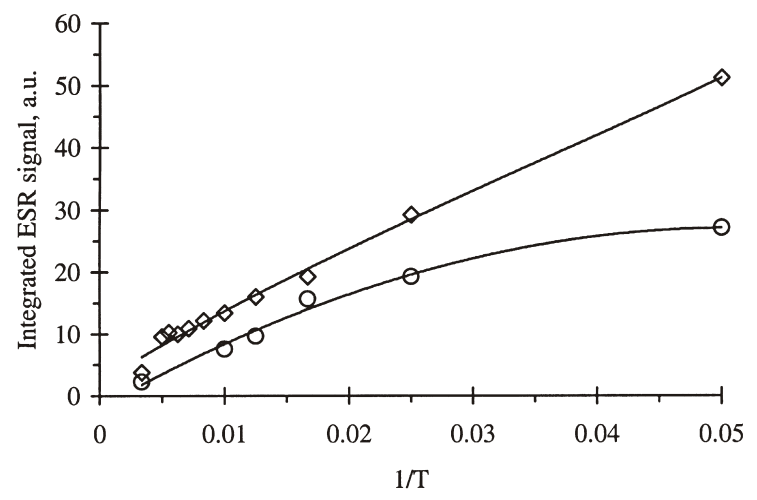

Figure 2. Double integral of ESR signals from silicaentrapped 'tar' from the tobacco $(\diamond)$ and $K$ salts-doped tobacco blend (o) samples
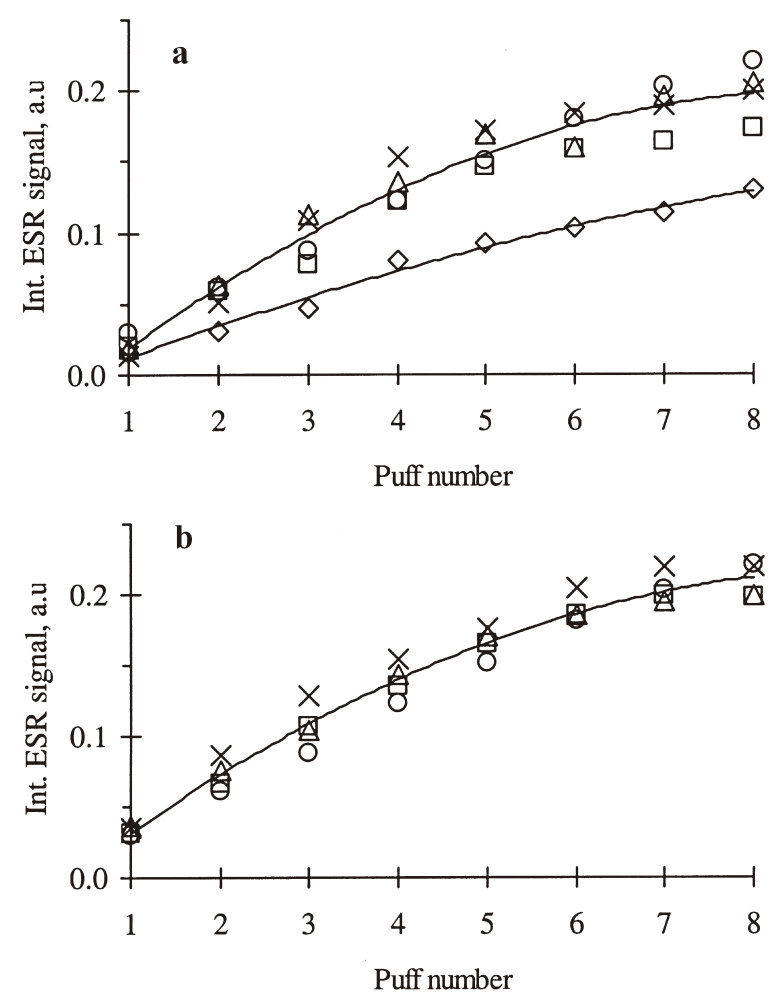

Figure 3. Integral intensity of ESR signal from 'tar' collected from (a) cellulose sheet (CS) $(\diamond)$ and (b) tobacco blend (TB) (o) samples, doped with glucose at $10 \%(\square), 15 \%(\Delta)$ and $20 \%(x)$

\section{RESULTS AND DISCUSSION}

Deviation from paramagnetic behavior of radicals in 'tar'

ESR spectroscopy was used to obtain information on radicals in the particulate phase of mainstream smoke. Spectra were also collected from 'tar' prepared from TB modified with $\mathrm{KHCO}_{3} / \mathrm{KCl}$ salts. These salts promote low-temperature cleavage of tobacco (38), possibly releasing more phenolic compounds. The ESR spectra were measured at temperatures from -253 to $25{ }^{\circ} \mathrm{C}$, while rapidly and randomly changing temperature to avoid systematic errors. Under these conditions, especially at sub-ambient temperatures, a slow spontaneous decay of radicals in 'tar' (36) could be disregarded. The 'tar' signal was assumed to be a superposition of several signals, broadened by atmospheric $\mathrm{O}_{2}$. The temperature dependence of the magnetic susceptibility $(\chi)$ of 'tar' samples was calculated by integrating ESR signals. A linear $\chi \sim T^{-1}$ dependence for the reference 'tar' sample, shown in Figure 2, indicated almost true paramagnetic behavior (Curie's Law). This implies that the radicals were diluted and did not undergo noticeable intra-molecular interactions. Deviation from paramagnetic behavior was observed for the $\mathrm{K}$ salt-modified sample.

Radicals in 'tar' include the Q- $\mathrm{QH}_{2}-\mathrm{HQ} \bullet$ complex, isolated semiquinone radicals and PAH-based radicals (39). Whereas the isolated radicals must behave as paramagnetic species, the $\mathrm{Q}-\mathrm{QH}_{2}-\mathrm{HQ} \cdot$ complex contains radicals at the temperature of measurement in the amounts dependent on the temperature-determined equilibrium in $\mathrm{QH}_{2}+\mathrm{Q} \leftrightarrow$ HQ•. This equilibrium may shift to the left at cooling, providing non-linearity to the magnetic susceptibility versus temperature curve. Such a shift could simulate a transition to the diamagnetic ground state of 'tar'. The nonlinearity of $\chi \sim T^{-1}$ was also observed for the 'tar' samples that were aged for a few days; the linear part of this dependence almost disappeared. These results may be explained by a greater stability of the Q- $\mathrm{QH}_{2}-\mathrm{HQ} \cdot$ complex, whereas isolated PAH-based radicals disappear relatively fast. This model is consistent with (39), where $80 \%$ of the ESR signal from a similar sample was attributed to the semiquinone-containing redox complex.

Time-resolved ESR measurements of radicals in 'tar' collected from sequential puffs from one cigarette smoked under FTC conditions were collected. The amount of radicals accumulating during a single puff always decreased as the puff number increased, as seen from a decreasing slope of the curves in Figure 3. On the other hand, the 'tar' yield from each consecutive puff was found to increase. The decreasing concentration of radicals in 'tar' may suggest that the radical-containing 'tar', which is deposited on tobacco downstream by smoke, can interact and destroy the newly formed radicals, so that fewer numbers of them can be detected.

\section{Glucose}

As is seen in Figures 4(a,b), addition of glucose directly into the TB resulted in suppression of the heat output. For the CS sample, this suppression was much smaller. No additional processes or significant changes in the relative rates of exothermic processes were observed. The suppression of oxidation can tentatively be attributed to additional diffusion limitations to oxygen. Such limitations can be introduced by a glucose film, which could stay on the surface of CS or TB particles up to $400-450{ }^{\circ} \mathrm{C}$ in a caramelized form. The MS analysis of the combustion products showed no significant changes in the combustion chemistry due to the additional glucose.

Limitation of oxygen supply to parts of the combustion zone could affect its temperature profiles as well as the probability of generating radicals resulting from oxidation reactions. As seen in Figure 3a, the addition of glucose to the CS material resulted in about a $40 \%$ increase in the 'tar' radical yield, whereas for TB this change was insignificant. These results suggest that glucose is capable of generating radical precursors or radicals in 'tar'. One of the 

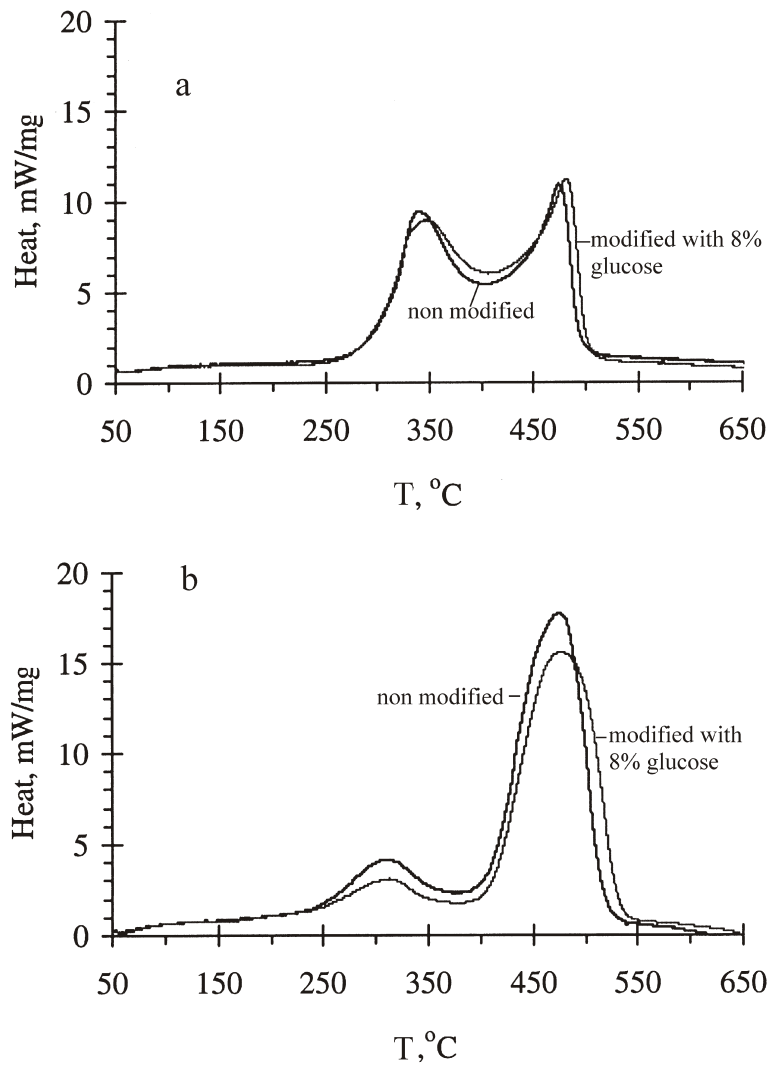

Figure 4. DSC of cellulose sheet (a) and tobacco blend (b), non modified and modified with $8 \%$ glucose

possible pathways could be the generation of semiquinonetype radicals via formyl- radicals produced directly from glucose. Interestingly, the amount of radicals generated in each puff from glucose-doped CS was found to be the same as from the unaltered TB. This may be explained by the fact that TB naturally contains low molecular weight carbohydrates, e.g., fructose.

The temperatures inside the burning cigarettes and on the surface of the firecone are shown in Table 3. Accuracy of these measurements entirely depended on the positioning of the thermocouple inside the cigarette or of the cigarette relative to the IR camera. Having measured 5 cigarettes for each sample type, we estimate a 10 and $30{ }^{\circ} \mathrm{C}$ error for TCT and IRT measurements, respectively. As seen from these data, incorporation of glucose into CS or TB does not affect the firecone surface temperature profiles significantly and only slightly changes the internal smolder temperatures. This suggests no obvious differences in radical formation on the surface of the combustion zone, where glucose as an additive must have been completely consumed. Glucose as a carbohydrate fuel is similar to the materials of the matrices and should not greatly alter their combustion heat. Nevertheless, a minor increase in the smolder temperature of CS can be explained by additional formation of some low-molecular weight, faster burning fuel from glucose. The smoldering temperature of untreated TB is higher than that of CS by approximately $140{ }^{\circ} \mathrm{C}$, which may happen due to the greater amounts of volatile combustibles in TB. Unlike the CS case, the addition of glucose to TB decreased the smolder temperature by about $60{ }^{\circ} \mathrm{C}$, suggesting that glucose could have been deposited on the surface of TB as a film, thus limiting $\mathrm{O}_{2}$ supply. This model is consistent with the explanation of suppression of oxidative decomposition of TB by glucose resulting from diffusion limitations to oxygen, as shown in Figure 4.

\section{Pectin}

Pectin, a complex carbohydrate, accounts for about $30 \%$ of the cell walls of many agricultural crops including tobacco. The addition of pectin to TB and to CS caused changes in heats measured by DSC, as shown in Figure 5. A substantial suppression of the heat at the peak maximum coincided with its broadening, which may indicate additional diffusion limitations. For comparison, pure pectin was investigated and showed a much lower and broader heat output at $450{ }^{\circ} \mathrm{C}$ than the TB- or CS-based samples, with the appearance of a new broad peak at $730{ }^{\circ} \mathrm{C}$ and a sharp peak at $750{ }^{\circ} \mathrm{C}$. No phenolic compounds were observed by MS from pure pectin. The observed peaks at 68,95 , and 97 amu probably correspond to furan derivatives. The MS spectra for all samples are available upon request.

The thermochemical properties of pure pectin were expected to be similar to those of another polysaccharide CS, which was studied earlier in connection with the ignition behavior of cellulose fabrics (38). DSC studies revealed three types of exothermic processes, i.e., oxidative depolymerization, cleavage to lower molecular weight fuels and combustion of gaseous carbohydrates. Direct combustion of char may be included as the fourth process type, which depends on the combustion conditions. DSC of pure pectin in this work showed similar characteristic peaks.

Table 3. Temperatures of smoldering samples that contain glucose: internal temperatures during free-smoldering and maximum fire cone temperature during puffing ${ }^{a}$

\begin{tabular}{|c|c|c|c|c|}
\hline \multirow{2}{*}{$\begin{array}{l}\text { Sample } \\
\text { (G = glucose) }\end{array}$} & \multicolumn{4}{|c|}{ Temperature, ${ }^{\circ} \mathrm{C}$} \\
\hline & Smoldering & Average TCT & Surface & Average IRT \\
\hline CS & 663 & 663 & 1261 & 1261 \\
\hline $\mathrm{CS}+10 \% \mathrm{G}$ & 702 & & 1122 & \\
\hline $\mathrm{CS}+15 \% \mathrm{G}$ & 655 & 682 & 1304 & 1234 \\
\hline $\mathrm{CS}+20 \% \mathrm{G}$ & 689 & & 1278 & \\
\hline $\mathrm{TB}$ & 802 & 802 & 1063 & 1063 \\
\hline $\mathrm{TB}+10 \% \mathrm{G}$ & 761 & & 1153 & \\
\hline $\mathrm{TB}+15 \% \mathrm{G}$ & 734 & 738 & 1018 & 1101 \\
\hline $\mathrm{TB}+20 \% \mathrm{G}$ & 720 & & 1131 & \\
\hline
\end{tabular}

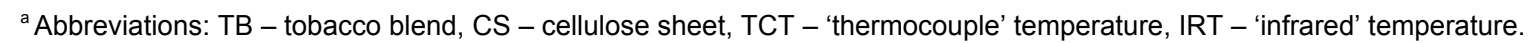



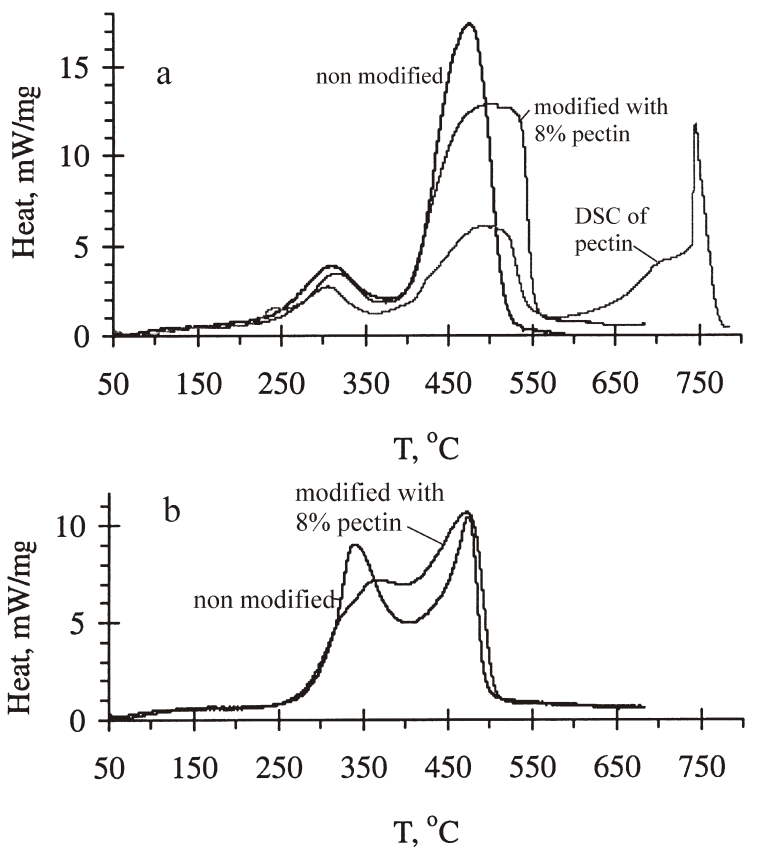

Figure 5. (a) DSC of tobacco blend (TB), non-modified, modified with $8 \%$ pectin, DSC of pectin; (b) DSC of cellulose sheet (CS), non-modified and modified with $8 \%$ pectin

However, additional peaks at 720 and $750{ }^{\circ} \mathrm{C}$ in Figure 5a are evidence of a greater number of oxidation processes in pectin. This may be interpreted as formation of a combustible fuel, encapsulated into a caramelized pectin-built shell, which can withstand the combustion conditions and release fuel when the shell is destroyed. This might be the cause of the unusually sharp $750{ }^{\circ} \mathrm{C}$ peak.

\section{Chlorogenic acid}

DSC of pure chlorogenic acid is shown in Figure 6. The low-temperature DSC curve shows two endothermic processes: melting at $200{ }^{\circ} \mathrm{C}$ and a gradual decomposition starting at $220{ }^{\circ} \mathrm{C}$. The products had a distinct phenol peak at 94 amu and also peaks at $82 \mathrm{amu}$ (2-methylfuran) and $110 \mathrm{amu}$ (dihydroxybenzene). Additional exothermic peaks at 380 and $4700^{\circ} \mathrm{C}$ may correspond to the combustion of vapor fuel and char, respectively.

The addition of chlorogenic acid to CS did not noticeably affect oxidative decomposition. Combustion of TB was inhibited at $340{ }^{\circ} \mathrm{C}$ by about $20 \%$. This inhibition may have been caused by the radical-scavenging activity of the catechol functional group in the chlorogenic acid molecule. This assumption was supported by the observed suppression of all volatile products in the range of 50-120 amu generated below $400{ }^{\circ} \mathrm{C}$ in both matrices. A somewhat greater amount of solid fuel was indicated by TG to remain in the DSC chamber at about $400{ }^{\circ} \mathrm{C}$ for the $\mathrm{CS}$ and TB samples containing chlorogenic acid than for samples without added chlorogenic acid. This greater amount of solid fuel could have resulted in a greater DSC intensity of the over $450{ }^{\circ} \mathrm{C}$ combustion for both CS and TB with chlorogenic acid.

\section{Lignin}

The polyphenolic material lignin, specified in different forms in Table 1, is a product of fermentation of chloro-

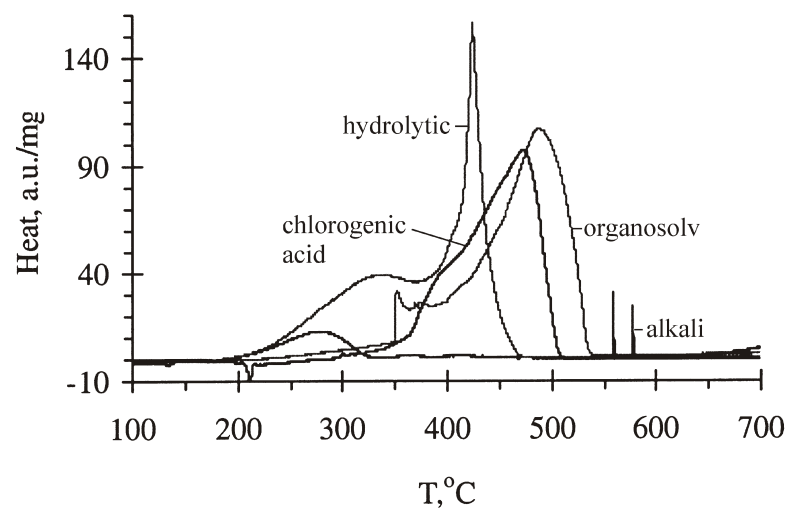

Figure 6. DSC of lignins ("organosolv", "alkali", "hydrolytic") and chlorogenic acid at a heating rate of $5{ }^{\circ} \mathrm{C} / \mathrm{min}$ in a flow of $39 \mathrm{~mL} / \mathrm{min}$ of $9 \% \mathrm{O}_{2}$ in $\mathrm{He}$

genic acid in the living plant; hence, lignin and chlorogenic acid are usually present together (8). Lignin molecules contain phenolic groups, which can be retained in a solid form longer that in the case of chlorogenic acid; thus these groups have a greater chance to undergo further combustion at higher temperature instead of being delivered in smoke. We expected that the comparison of the thermochemical behavior of the available lignins and chlorogenic acid could provide useful information about the possible contribution of lignins to the smoke phenols.

The heats of decomposition of three different lignins, shown in Figure 6, demonstrated quite different reactivities. Each lignin was actually a different substance from a specific plant source and was extracted under different conditions. Due to the significant differences in the properties of the studied lignins, they may not well represent the "tobacco" lignin. However, we believe that the lignin processes considered here most likely take place during tobacco combustion.

Lignin S was prepared from hardwood by extraction with organic solvents that made it drier than other samples. This might have contributed to its inactivity in oxidative cleavage below $350{ }^{\circ} \mathrm{C}$ as confirmed by TG/MS analysis. A very steep front on the first oxidation peak suggests participation of some form of internally stored oxidant in the sample, such as the hydroperoxide groups in cellulosic materials (38).

Unlike lignin S, lignin A demonstrated high activity in lowtemperature oxidative decomposition. It was produced from spruce wood by extraction with water solutions of alkali compounds, which are expected to promote decomposition of cellulosic material and cleavage of polyphenols. As seen from Figure 6, oxidation above $330{ }^{\circ} \mathrm{C}$ was not indicated except for intense, narrow peaks above $550{ }^{\circ} \mathrm{C}$. A rich array of volatile products, including the masses 62, 68, $94 \mathrm{amu}$, was measured by the mass-spectrometer. These signals were attributed to ethylene glycol, furan, and phenol, respectively. Hence, the lignin in the A-form could be a significant precursor to phenol in smoke.

Lignin $\mathrm{H}$, produced from water solutions of raw cane sugar, demonstrated unique combustion properties, as illustrated by Figure 6. It shows a low-temperature oxidative cleavage around $340{ }^{\circ} \mathrm{C}$ and combustion of the formed lower molecular weight fuel at $430{ }^{\circ} \mathrm{C}$. Lignin $\mathrm{H}$ formed a similar array of products as lignin $\mathrm{A}$, but in smaller amounts. 

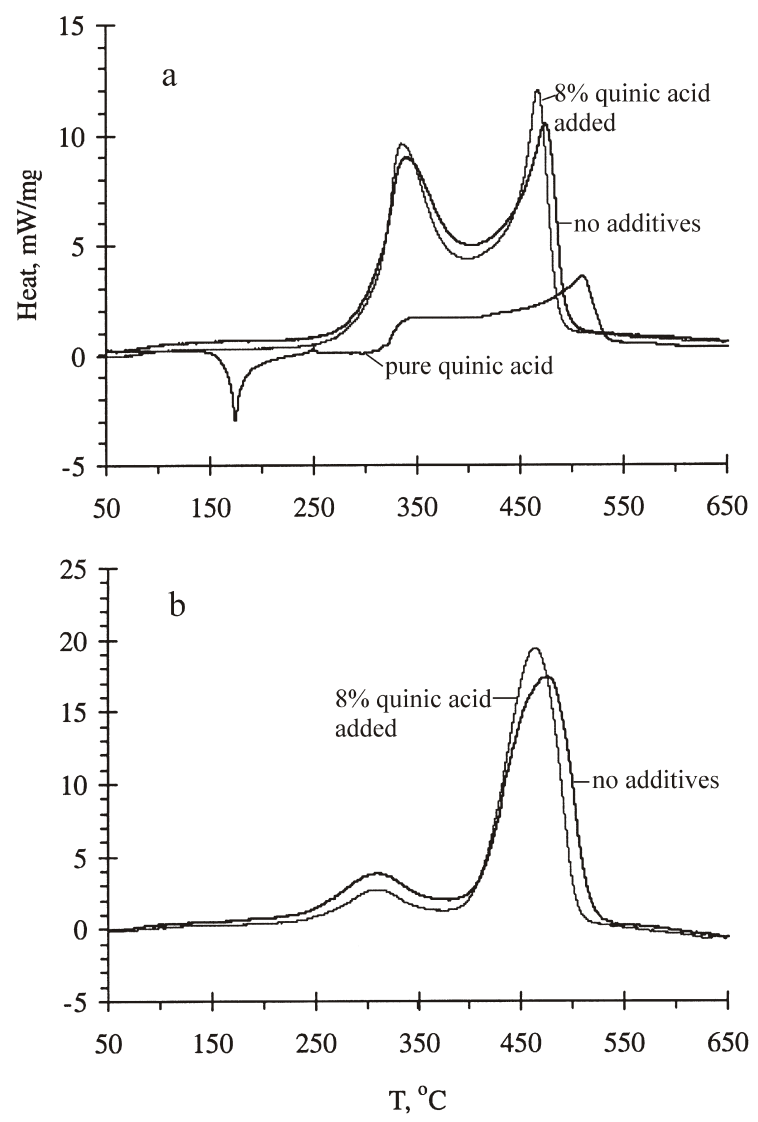

Figure 7. DSC of cellulose sheet (CS) (a) and tobacco blend (TB) (b) in $9 \% \mathrm{O}_{2}$ in $\mathrm{He}$ at $10{ }^{\circ} \mathrm{C} / \mathrm{min}$ heating rate; no additives, $8 \%$ quinic acid added, pure quinic acid

\section{Quinic acid}

Quinic acid represents the carbohydrate part of chlorogenic acid. The plant chemistry of quinic acid and its dehydrated form, shikimic acid, has been thoroughly investigated by GAMBORG (22) and more recently by BEGUM et al. (23); the phenol aromatic structures were shown to form from sugars at relatively low temperatures and the quinone structure served as a precursor to phenol. The DSC spectra of pure quinic acid, shown in Figure 7, exhibit a set of exothermic peaks, characteristic of carbohydrates, and one endothermic peak around $175^{\circ} \mathrm{C}$ shown by MS to represent simultaneous melting and dehydration processes.

Quinic acid addition caused an increase in the heat of combustion at $450{ }^{\circ} \mathrm{C}$ estimated by areas under the corresponding DSC peaks for CS and TB samples as 17 and $12 \%$, respectively. This increase in heat of combustion might be associated with the formation of additional radicals (formyl or semiquinone type) at low temperatures. Because the increase in the low molecular weight phenols yield due to addition of quinic acid was found to be significant, we assume that the increase in combustion heat was a quinone-semiquinone driven reaction.

Formation of more phenol, dihydroxybenzenes and corresponding quinones from pure quinic acid was indicated by the MS peaks at 94, 108 and $110 \mathrm{amu}$, in agreement with findings in $(22,23)$. The addition of quinic acid to TB resulted in some decrease in the yield of almost all products in the 50-120 amu range, which may be
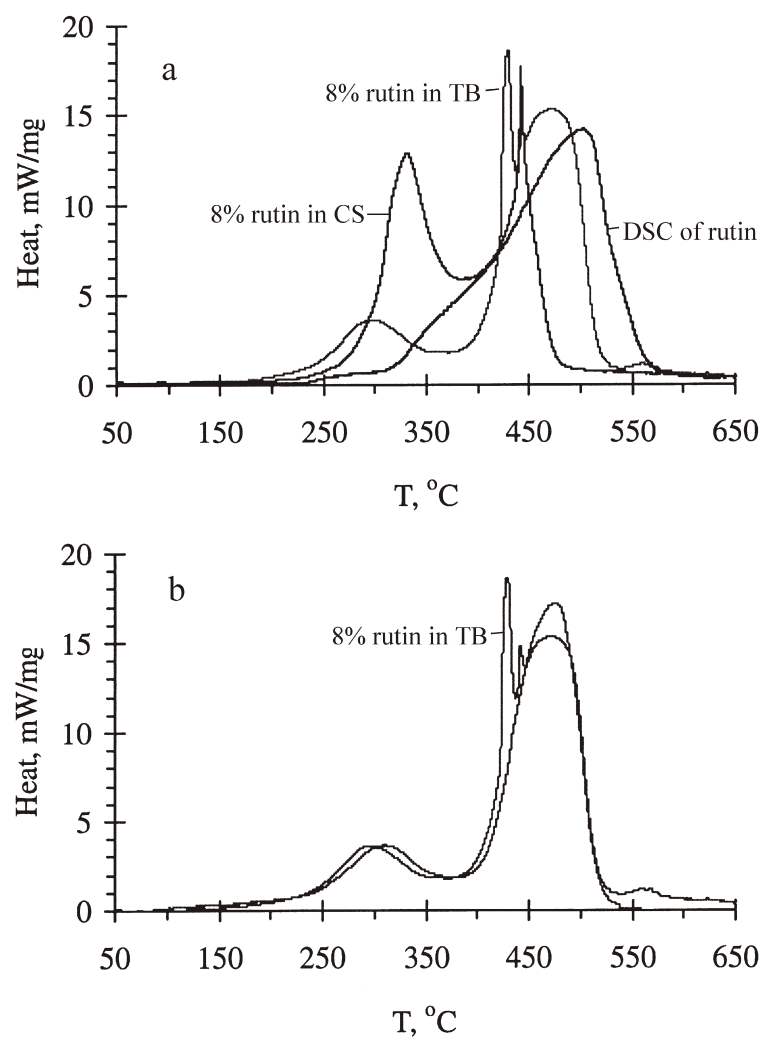

Figure 8. DSC of rutin, $8 \%$ rutin in cellulose sheet (CS) and tobacco blend (TB) samples in $9 \% \mathrm{O}_{2}$ in $\mathrm{He}$.

associated with the observed $29 \%$ suppression of TB decomposition at $300{ }^{\circ} \mathrm{C}$. In additional cigarette tests under FTC conditions, it was found that quinic acid, introduced to the TB fuel, increased the yield of hydroquinone and catechol. The low-temperature phenols formed from quinic acid may provide this inhibition of oxidative cleavage indicated by the decreased yield of products.

The formation of acetic acid from quinic acid observed by DEMIRBAS (40) under similar conditions was attributed to the elimination of acetyl groups originally linked to the xylose units. Acetic acid (60 amu) did not show a change in our DSC experiment when quinic acid was added to the TB fuel. This suggests that elimination of acetyl groups may not involve additional oxidation and, therefore, was not affected by the addition of a phenolic radical scavenger in the form of quinic acid. MS showed that almost all phenols, which resulted from pure quinic acid, were consumed in the presence of TB under the DSC conditions. This finding supports the participation of these phenols in radical scavenging reactions.

\section{Rutin}

Rutin is a phenolic material which also contains a carbohydrate moiety. Figure 8 a shows that the most pronounced exothermic peak completely disappeared when rutin was added to CS or TB. Instead, two new sharp peaks emerged at 430 and $450{ }^{\circ} \mathrm{C}$ on the rutin-TB curve and at $450{ }^{\circ} \mathrm{C}$ on the rutin-CS curve. As is seen from Figure $8 \mathrm{~b}$, introduction of rutin slightly suppressed the TB oxidation around $500{ }^{\circ} \mathrm{C}$, but initiated the oxidation processes at 430 and $450{ }^{\circ} \mathrm{C}$. 


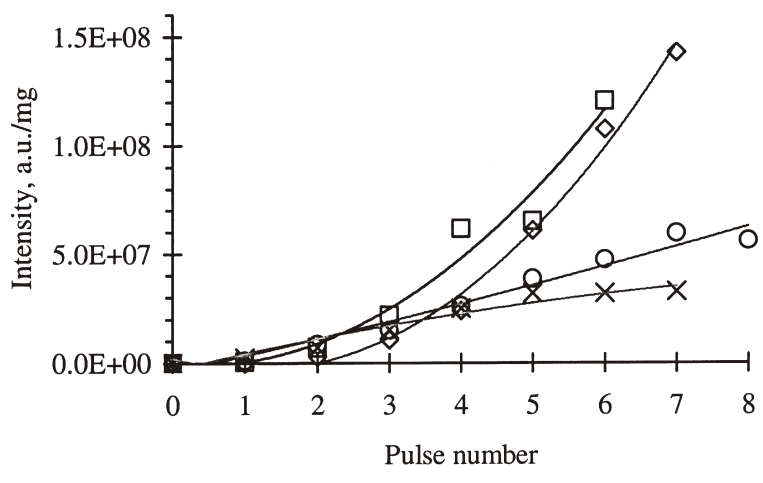

Figure 9. Integral intensities of ESR signal from 'tar' collected on silica from combusted cellulose sheet (CS, $\square$ ), tobacco blend (TB, $\Delta$ ), and $8 \%$ rutin doped CS $(O)$ and TB $(X)$

We assume that in rutin the combustion-inhibiting activity is caused primarily by its catechol and resorcinol groups. The two new exothermic processes could be initiated by the products of rutin cleavage and oxidation. The likely radical that could participate in these reactions, is the catecholderived semi-o-quinone. In order to test this assumption, we monitored the MS spectra of the products with increasing temperature. The products of the oxidative decomposition of rutin contained an 82 amu fragment, which can be attributed to 2- or 3-methylfuran, formed as a result of intra-molecular rearrangements of phenols. These compounds were also formed from TB and CS, but were noticeably suppressed in the presence of rutin.

Decomposition of pure rutin also showed formation of hydroquinone, resorcinol or catechol (110 amu), quinone and semiquinone (108 and $109 \mathrm{amu}$ ) in relatively small amounts; this is likely because of secondary reactions, which resulted in their consumption. In the products from rutin-doped TB and CS, the $110 \mathrm{amu}$ peak was not present. We assume that dihydroxybenzenes reacted with the products from TB of CS (inhibiting activity), and generated or initiated new oxidation paths which were observed as the 430 and $450{ }^{\circ} \mathrm{C}$ exothermic DSC peaks in Figure 8.

The possibility of introduction of some new reactions is supported by several additional mass fragments, e.g., 58 amu, which increased in the mass spectrum of the CS-based sample when rutin was added. These could indicate the presence of several $\mathrm{C} 2-\mathrm{C}_{4}$ hydrocarbons, alcohols and aldehydes. In the case of TB, the same $58 \mathrm{amu}$ fragment decreased after rutin was added, showing that suppression of oxidation by phenols may prevail in some parts of the combustion mechanism. Overall, the results suggest that new exothermic processes can be initiated by the products of rutin cleavage and oxidation. It is likely that the catechol-derived semi-o-quinone participated in or even initiated these reactions. Additionally, resorcinol as a part of rutin may act as an inhibitor in the system.
The ESR measurements of 'tar' from cigarette samples showed that the presence of rutin both in TB and in CS noticeably suppressed the formation of radicals. This observation supports the assumption of scavenging activity by catechol and resorcinol present in rutin. Figure 9 shows the average accumulation of smoke radicals for each of these four samples. The effects of rutin are further verified by the data in Table 4, which shows the average total amount of radicals from each sample. The data represent the integrated intensity of the signal collected over 20 scans in order to maximize the accuracy of the radical estimation. The data are shown normalized to the amount of particulate matter collected. Interestingly, the degree of radical suppression was found to be much greater in the case of the TB-based fuel samples at $34 \%$ than it was for the CS fuel, at $18 \%$. This can be explained by a larger radical yield produced from TB (evident from Figure 9 and Table 4) than from CS.

\section{Quercetin}

Quercetin was investigated as a representative of the phenolic part of rutin. The DSC spectrum of pure quercetin showed an endothermic dehydration at $120^{\circ} \mathrm{C}$ and several exothermic oxidative processes with a major combustion peak at $450{ }^{\circ} \mathrm{C}$. The presence of $\mathrm{CS}$ and TB matrices dramatically altered this DSC pattern of isolated quercetin. This change was accompanied by a small increase of the combustion process of CS around $470{ }^{\circ} \mathrm{C}$, which was verified by an increase in the gas products released in the 50120 amu range.

This change could result from the formation of an additional semiquinone-type radical from quercetin, similar to that from rutin. This possibility is supported by additional mass fragments observed around $109 \mathrm{amu}$ in the quercetindoped CS combustion products. Addition of quercetin to TB did not change the MS spectrum, probably because of a higher concentration of radicals in the combustion products of the original TB.

Interestingly, MS plots of the decomposition products from pure quercetin exhibited no molecular fragments within the range of 50-120 amu. Considering the rich product spectrum from rutin, we may assume the difference in the behavior between these two structurally similar compounds is due to the presence of a large rutinose moiety in the rutin structure. This carbohydrate group probably diluted phenolic groups in rutin, promoting their cleavage and release to smoke. Otherwise, a greater concentration of the reactive functional groups would cause rapid polymerization and retention of quercetin in the combustion zone until it burns with no products released in 50-120 amu range.

\section{Caffeic acid}

Caffeic acid is the phenolic part of chlorogenic acid, which together with quinic acid could provide a more complete

Table 4. Average total concentration of radicals in 'tar' from control and rutin-modified fuel samples

\begin{tabular}{|c|c|c|c|}
\hline \multirow[b]{2}{*}{ Sample } & \multirow{2}{*}{$\begin{array}{c}\text { Integral ESR Signal } \\
\text { per cig, a.u. }\end{array}$} & \multicolumn{2}{|c|}{ Integral ESR Signal per 1 mg 'tar' } \\
\hline & & a.u. & $\%$ change \\
\hline Tobacco blend & 4.009 & 0.174 & - \\
\hline $8 \%$ rutin - tobacco blend & 3.047 & 0.105 & 33.9 \\
\hline Cellulose sheet & 2.912 & 0.108 & - \\
\hline $8 \%$ rutin - cellulose sheet & 3.348 & 0.089 & 17.6 \\
\hline
\end{tabular}



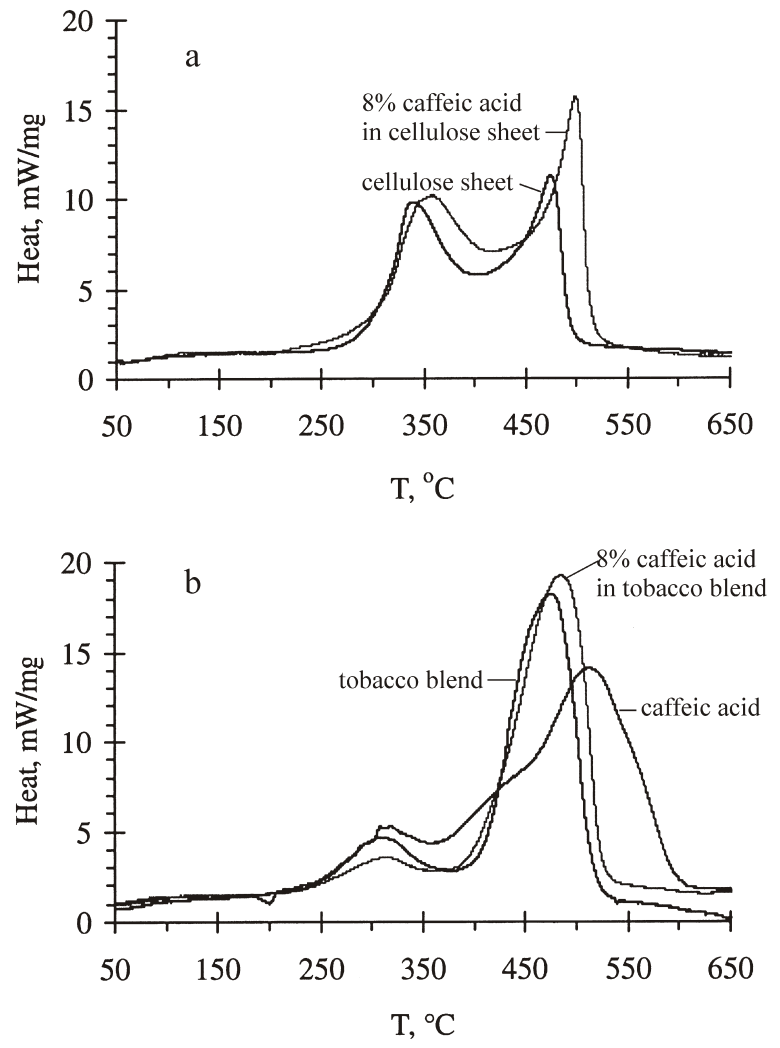

Figure 10. DSC of samples in $9 \% \mathrm{O}_{2}$ in $\mathrm{He}$ at a heating rate of $10^{\circ} \mathrm{C} / \mathrm{min}$; (a) cellulose sheet (CS), $8 \%$ caffeic acid in CS; (b) tobacco blend (TB), $8 \%$ caffeic acid in TB, and caffeic acid

thermochemical picture for chlorogenic acid. The DSC spectrum of pure caffeic acid is shown in Figure 10. This compound provided peaks of oxidative cleavage at $300{ }^{\circ} \mathrm{C}$ and combustion around $510^{\circ} \mathrm{C}$. The latter peak disappeared in the presence of CS or TB as matrices.

Pure caffeic acid did not generate products in the 50-120 mass range, suggesting that products more stable at high temperatures, such as PAHs, formed. This result is in agreement with the thermal behavior of bulk catechol or quercetin, close relatives to caffeic acid. Therefore, the chemical reactivity of bulk caffeic acid in a radical-driven polymerization is probably determined by the vicinal hydroxyls. The difference between the thermal behavior of caffeic acid and chlorogenic acid is probably determined by the presence of the quinic acid moiety in the latter compound. This group may prevent the catechol group from polymerization, similar to that in rutin.

\section{Individual phenols}

Experiments with phenol, resorcinol, hydroquinone and catechol were undertaken to better understand possible secondary reactions of the individual phenols formed during combustion of fuels. DSC spectra of these phenols in an oxidizing atmosphere under conditions specified above in the Experimental Section were obtained. The typical DSC/MS graphs for catechol are shown in Figure 11; the plots for phenol, resorcinol and hydroquinone can be obtained upon request. The predominant processes for the individual phenols are endothermic and can be attributed to the melting and boiling of the individual phenols. Table 5 contains the measured DSC peak temperatures along with
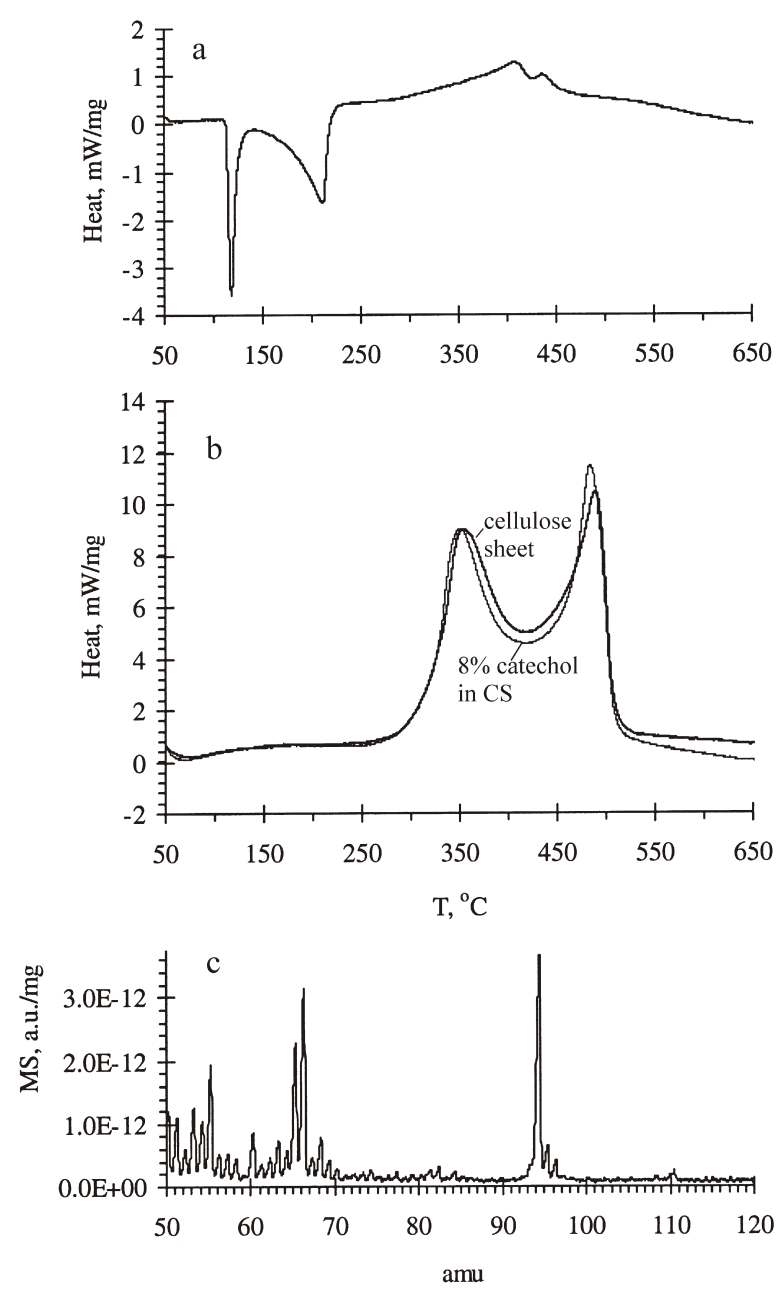

Figure 11. DSC of the products obtained at $10{ }^{\circ} \mathrm{C} / \mathrm{min}$ heating rate in $9 \% \mathrm{O}_{2}$ in He from (a) catechol; (b) from cellulose sheet (CS) and $8 \%$ catechol in CS; (c) MS analyses of the products from catechol

the fairly close phase transfer temperatures of the samples from (41).

The measured temperatures appeared somewhat lower, especially for the boiling points, because the DSC/TG experiments were performed in a gas flow, which forced a large percentage of the phenols to escape from combustion chamber. Some noticeable exothermic oxidation was indicated in the cases of hydroquinone at $416^{\circ} \mathrm{C}$ and catechol at 397 and $426^{\circ} \mathrm{C}$. Both of these compounds appeared to be the most reactive among those tested.

Phenol was vaporized at around $136{ }^{\circ} \mathrm{C}$ and was measured by MS. Resorcinol did not show its molecular $110 \mathrm{amu}$ mass, but instead underwent cleavage to phenol (94 amu). The highly reactive hydroquinone did not form phenol and did not undergo extensive cleavage. Instead, it generated quinone (presumably, $p$-quinone). This highly reactive catechol underwent oxidative polymerization while in the DSC chamber, as indicated in Figure 11a. As a result, none of this compound or its oxidative decomposition products was measured. We assume that catechol is prone to produce non-volatile PAHs, whereas the 1,4-isomer produced $p$-quinone, and possibly semiquinone in 'tar'.

The DSC/MS spectra of the combustion products from CS with added phenol appear unaltered, probably because phenol could escape from the DSC reactor at low temper- 
Table 5. Temperatures of boiling and melting points of pure phenols

\begin{tabular}{|c|c|c|c|c|}
\hline \multirow[b]{2}{*}{ Sample } & \multirow[b]{2}{*}{ Process } & \multicolumn{2}{|c|}{ Reference data, ${ }^{\circ} \mathrm{C}(41)$} & \multirow[b]{2}{*}{ Experiment, ${ }^{\circ} \mathrm{C}$} \\
\hline & & At atm. pressure & At 16 torr & \\
\hline \multirow[t]{2}{*}{ Phenol } & melting & 43 & - & 37 \\
\hline & boiling & 182 & - & 136 \\
\hline \multirow[t]{2}{*}{ Resorcinol } & melting & 111 & - & 107 \\
\hline & boiling & - & 178 & 238 \\
\hline \multirow[t]{2}{*}{ Hydroquinone } & melting & 173 & - & 170 \\
\hline & boiling & 285 & - & 221 \\
\hline \multirow[t]{2}{*}{ Catechol } & melting & 105 & - & 104 \\
\hline & boiling & 245 & - & 198 \\
\hline
\end{tabular}
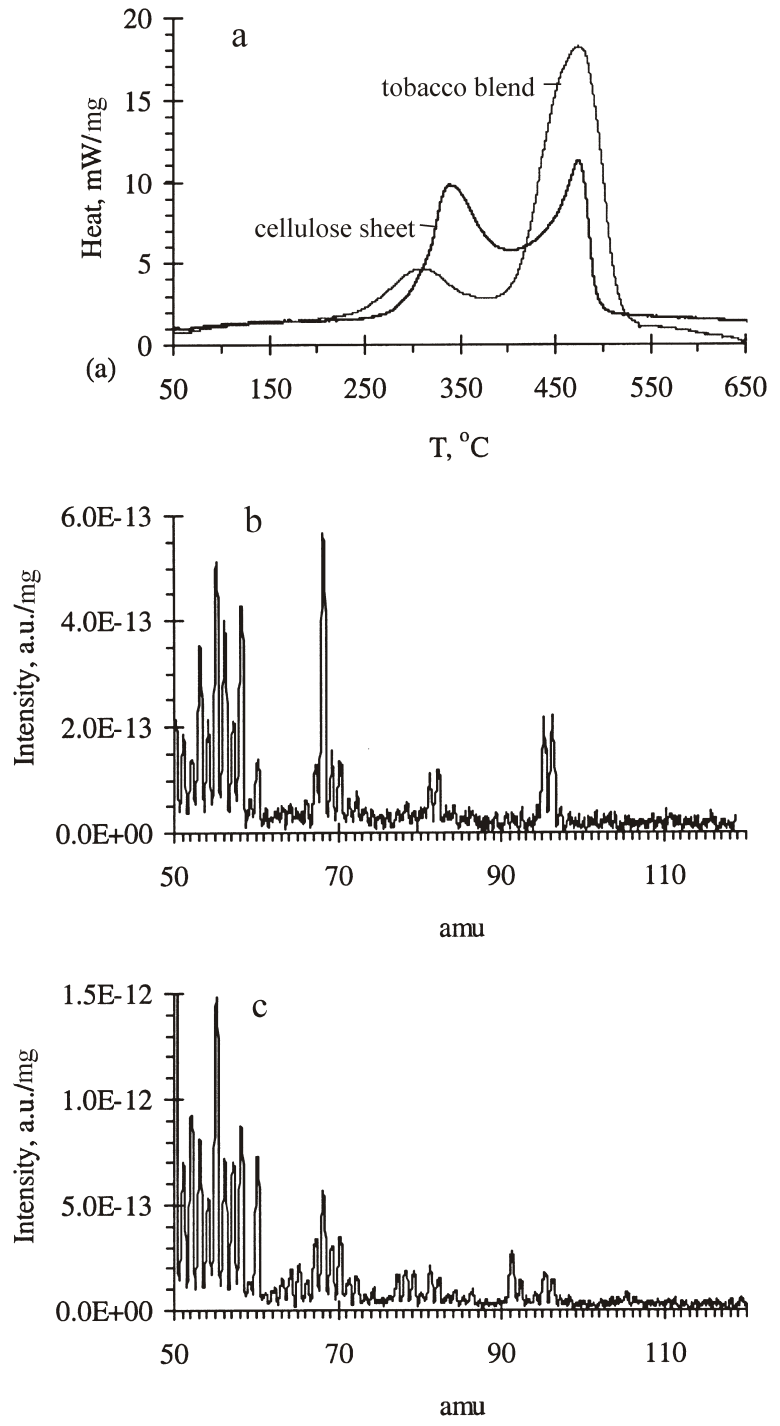

Figure 12. DSC (a) of the products from tobacco blend (TB) and cellulose sheet $(C S)$; MS $(b, c)$ of the products from CS (b) and TB (c)

ature, as shown for the pure material. Modification of TB with phenol, however, resulted in suppression of lowtemperature oxidation by $40 \%$, in an increase in the $450-500{ }^{\circ} \mathrm{C}$ oxidation, and in the formation of volatile products in the $50-120$ amu mass range by $20-30 \%$ as seen from Figures $12 \mathrm{c}$ and 13. The effect of phenol addition may include new reactions of phenoxy and hydrogen radicals, formed from phenol (42).
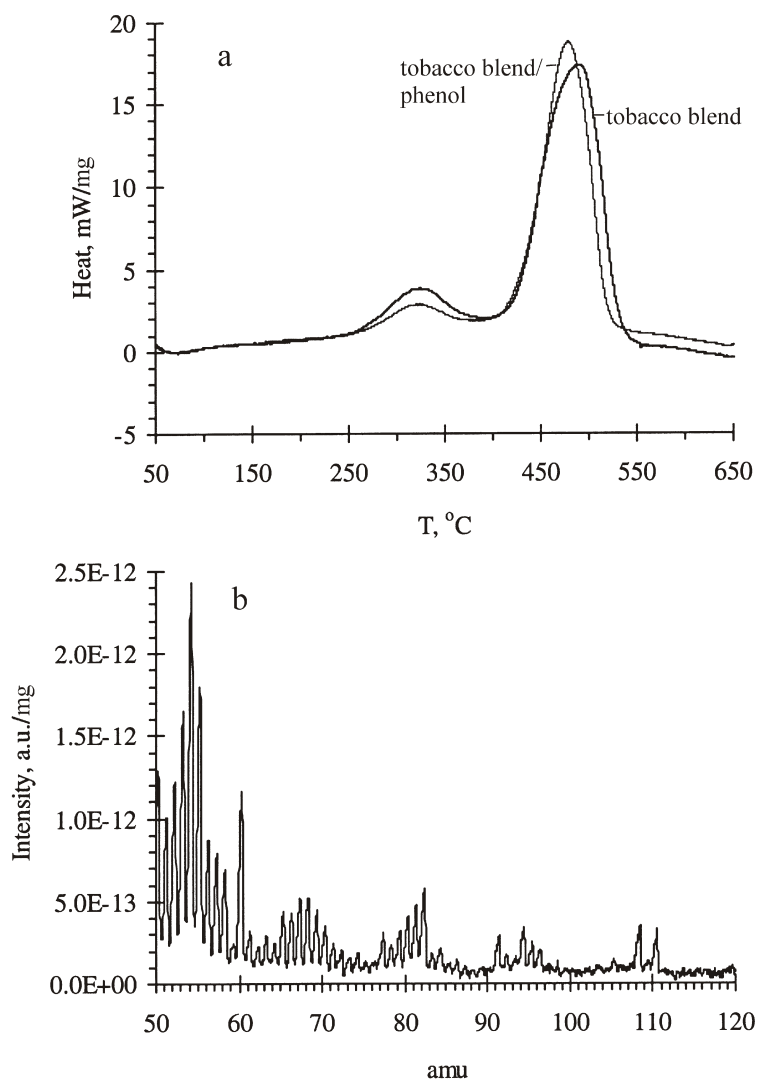

Figure 13. DSC (a) of the products from tobacco blend (TB) and TB/phenol; MS (b) of the products from TB/phenol

The radical scavenging/initiating effects of phenol may become more significant under cigarette combustion conditions. The concentration of radicals, including hydroxyls in the combustion zone of burning fuel is much greater than that in the DSC chamber. The addition of phenol to tobacco packed in a cigarette may scavenge hydroxyl radical, which is the most active radical in combustion, and produce quite inactive phenoxy and hydrogen radicals, thereby inhibiting the overall process:

$$
\begin{aligned}
& \text { Phenol } \leftrightarrow \text { Phenoxy } \bullet+\mathrm{H} \bullet \\
& \text { Phenol }+\mathrm{HO} \bullet \leftrightarrow \text { Phenoxy } \bullet+\mathrm{H}_{2} \mathrm{O} \\
& \mathrm{H} \bullet+\mathrm{HO} \bullet \leftrightarrow \mathrm{H}_{2} \mathrm{O}
\end{aligned}
$$

Addition of resorcinol to CS slightly intensified the exothermic processes. Similar to phenol addition, the enhancement of the oxidation at $450-500{ }^{\circ} \mathrm{C}$ appeared more pronounced in the case of resorcinol-modified TB. This enhancement was accompanied by a $20 \%$ increase in formation of the volatile products in the 50-120 amu mass range. Unlike pure resorcinol, which decomposed to phenol, the CS- or TB-sup- 

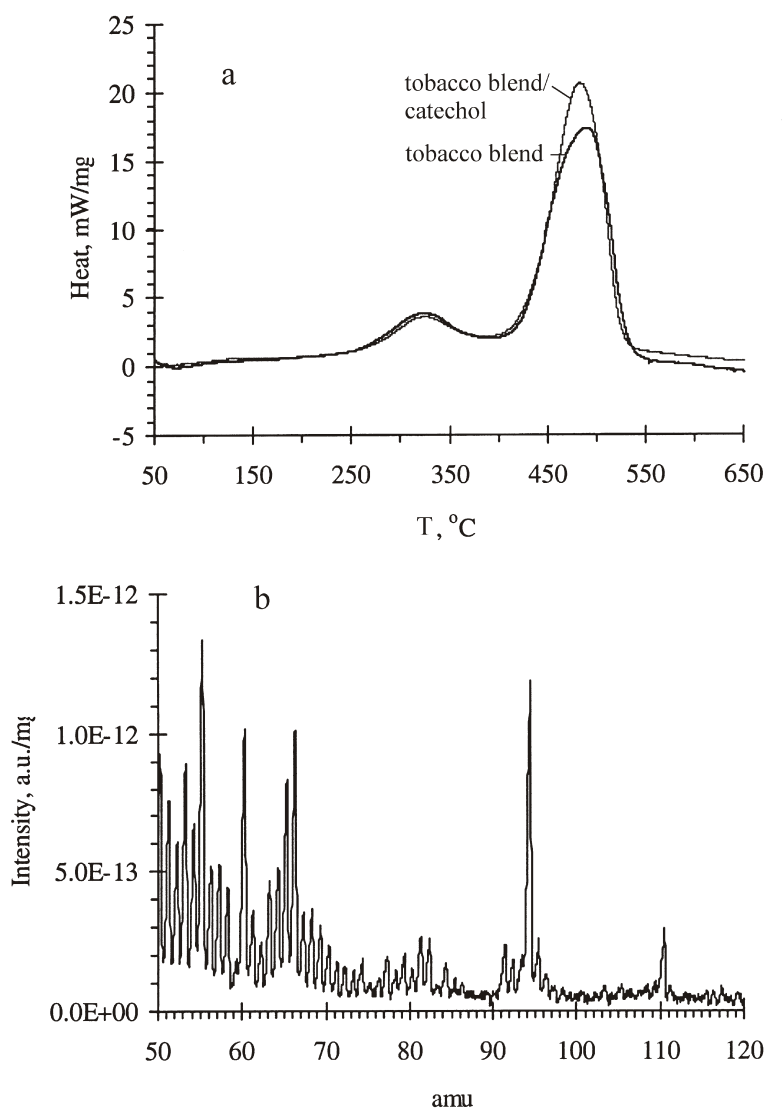

Figure 14. DSC (a) of the products from tobacco blend (TB) and TB/catechol; MS (b) of the products from TB/catechol

ported resorcinol produced the mass of $110 \mathrm{amu}$, which was the original compound or a product its isomerization.

Hydroquinone showed a weak promoting effect on the CS combustion and some inhibition of oxidation of TB. Correspondingly, the increase in the volatiles in the 50-120 amu range for $\mathrm{CS}$ and their decrease for TB were observed. In the case of CS, significant amounts of hydroquinone (110 amu) and quinone (108 amu) were measured.

The addition of catechol to CS and to TB also facilitated exothermic oxidation as seen in Figures $11 \mathrm{~b}$ and 14a. Unlike the pure material, which could undergo polymerization to PAH, the diluted catechol showed some cleavage and underwent oxidation reactions; as seen in Figures 11c and $14 \mathrm{~b}$, these reactions resulted in the formation of significant amounts of phenol (94 amu) in both CS and TB matrices and quinone in TB. Catechol and, possibly, the products of its isomerization, hydroquinone and resorcinol, were also found as the mass of $110 \mathrm{amu}$.

\section{Guaiacol}

In spite of some similarities in their structures, guaiacol (phenolic ether) and catechol affected TB and CS combustion differently. This could be caused by guaiacol's greater stability to polymerization, its high volatility, and its possible sensitivity to the acidity of the fuel and products of its low temperature oxidative cleavage. The presence of a methoxy group could prevent the formation of $o$ quinone and, therefore, the yield of the corresponding semiquinone radical. This situation may change in an acidic medium when demethylation yields catechol.
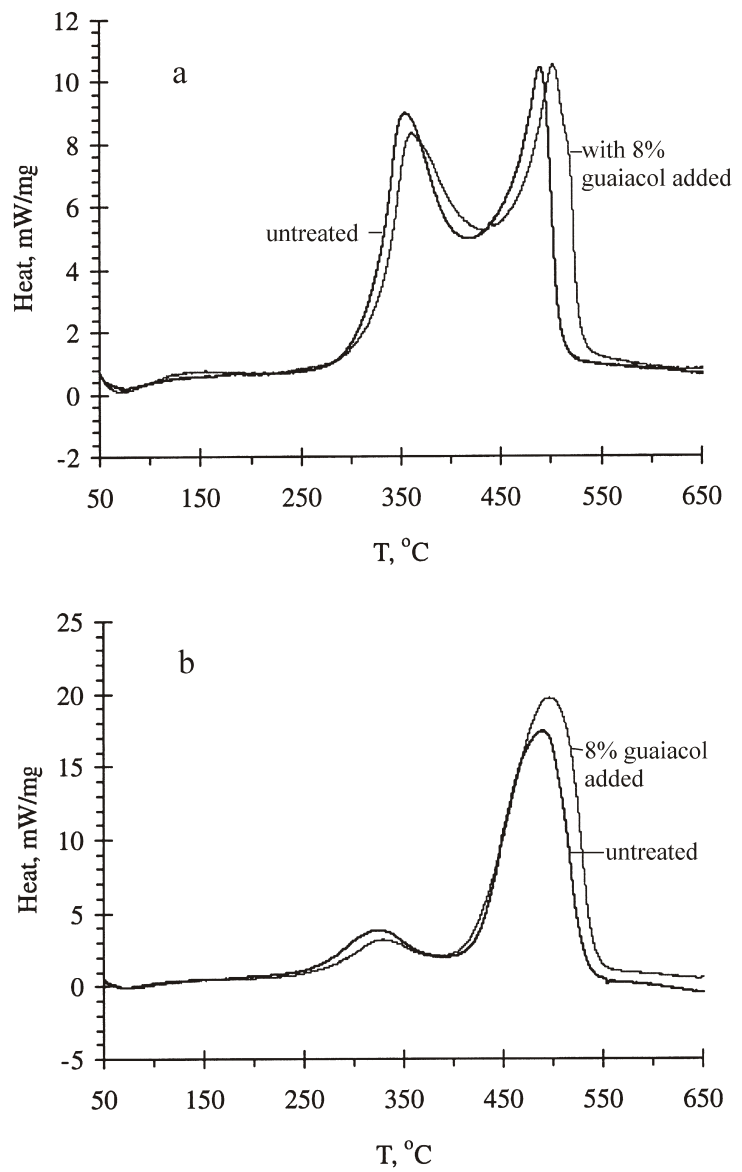

Figure 15. DSC of (a) cellulose sheet (CS) and (b) tobacco blend (TB): untreated, and with $8 \%$ guaiacol added

Figure 15a shows the DSC curves from CS fuel and the same material modified with guaiacol. A slight suppression of oxidation at $340{ }^{\circ} \mathrm{C}$ and a shift of the $470{ }^{\circ} \mathrm{C}$ maximum to a higher temperature resulted from the inhibitory activity of guaiacol. An additional amount of distilled guaiacol was found in the CS products. This suggests that guaiacol did not interact with the fuel matrix and only affected combustion of $\mathrm{CS}$ to a minor extent. As shown in Figure 15b, addition of guaiacol to the tobacco fuel caused a suppression of the low temperature oxidation exothermic processes and enhanced $470{ }^{\circ} \mathrm{C}$ combustion; these conclusions were supported by TG measurements. A new mass of $128 \mathrm{amu}$, tentatively attributed to tetramethyltetrahydrofuran, was observed in the combustion products.

\section{Polyaromatic hydrocarbons}

Experiments with pure naphthalene, anthracene, phenanthrene, and benzo $[a]$ pyrene $(\mathrm{B} a \mathrm{P})$ were performed in an oxidizing atmosphere at 10 and $60{ }^{\circ} \mathrm{C} / \mathrm{min}$ ramping rate. The measured temperatures of the endothermic melting and boiling, shown in Table 6, appear to be fairly close to the reference data from (41). The absence of any exothermic peaks in the case of naphthalene, anthracene and phenanthrene indicated high stability of these compounds even in an oxidative atmosphere as supported by MS analysis. $\mathrm{B} a \mathrm{P}$ is the only $\mathrm{PAH}$ that showed some activity in oxidation around $650{ }^{\circ} \mathrm{C}$; this could be explained by less volatile impurities, e.g., quinone type compounds. 
Table 6. Temperatures of endothermic processes in pure aromatic hydrocarbons at atmospheric pressure, unless specified

\begin{tabular}{|c|c|c|c|c|c|}
\hline \multirow[b]{2}{*}{ Sample } & \multirow[b]{2}{*}{ Process } & \multicolumn{2}{|c|}{ Reference data, ${ }^{\circ} \mathrm{C}$} & \multicolumn{2}{|c|}{ Experimental peaks at } \\
\hline & & At atm. pressure & At lower pressure & $10^{\circ} \mathrm{C} / \mathrm{min}$ & $60^{\circ} \mathrm{C} / \mathrm{min}$ \\
\hline \multirow[t]{2}{*}{ Naphthalene } & melting & 81 & - & 94 & 145 \\
\hline & boiling & 218 & $88 / 10$ torr & $\geq 182$ & 299 \\
\hline \multirow[t]{2}{*}{ Anthracene } & melting & 216 & - & 227 & - \\
\hline & boiling & 340 & $227 / 53$ tor & $\geq 277$ & - \\
\hline \multirow[t]{2}{*}{ Phenanthrene } & melting & 101 & - & 111 & 278 \\
\hline & boiling & 340 & $210 / 12$ tor & $\geq 275$ & 388 \\
\hline \multirow[t]{4}{*}{ Benzo[a]pyrene (BaP) } & melting & 179 & - & - & 238 \\
\hline & boiling & - & $310 / 10$ tor & - & 498 \\
\hline & exotherm & - & - & - & 636 \\
\hline & exotherm & - & - & - & 688 \\
\hline
\end{tabular}

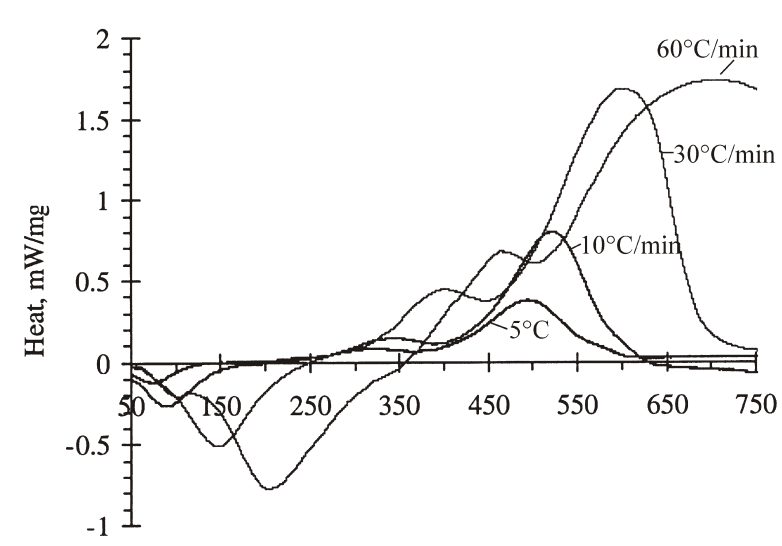

$\mathrm{T},{ }^{\circ} \mathrm{C}$

Figure 16. DSC of the alumina-supported benzo[a]pyrene at the temperature ramping rates of $5,10,30$ and $60^{\circ} \mathrm{C} / \mathrm{min}$. Similar DSC curves for other PAHs are available

Investigation of oxidation processes of PAHs in model systems with a relatively slow temperature ramping rate is complicated by the high volatility of the hydrocarbons, i.e., they can escape from the combustion zone (DSC chamber) before the combustion conditions are reached. A non-combustible matrix, alumina, was used to retain the PAHs in the reactor until they are exposed to the highest available temperatures in the DSC/TG chamber.

Typical DSC spectra of $\mathrm{B} a \mathrm{P}$ in an oxidizing atmosphere are shown in Figure 16 at four different temperature ramping rates as of $5,10,30$ and $60{ }^{\circ} \mathrm{C} / \mathrm{min}$; the DSC results for all PAHs are available upon request. The TG curves indicated a gradual weight loss during the temperature ramps, but showed no other significant features. The analysis of the decomposition products did not show peaks in the 50-120 amu range; instead, $\mathrm{CO}_{2}$ and water yields indicated combustion. This implies that fused aromatics do not undergo cleavage, but rather a complete oxidation via the reactive oxygen-containing intermediates, such as quinones, anhydrides, acids.

As seen in Figure 16, one endothermic and three exothermic processes, which are included in the network of thermochemical reactions of aromatic compounds, were observed. By applying different temperature ramping rates (HR), we determined the activation energies of these partial processes. Table 7 contains experimentally measured temperature maxima $\left(T_{\max }\right)$ of heat absorption and the calculated specific heats using the expression $\operatorname{Ln}\left(T_{\max }{ }^{2} / \mathrm{HR}\right)=$ $\left.E / R \cdot T_{\max }\right)+\operatorname{Ln}(E / A)(38)$. The temperatures and enthalpies of PAH fusion are provided for a comparison. The corresponding logarithmic plots are shown in Figure 17.

The endothermic processes, characteristic of all four PAHs, had an activation energy of $19 \mathrm{~kJ} / \mathrm{mol}$. Another process of $30 \mathrm{~kJ} / \mathrm{mol}$ was measured for phenanthrene. The first heat absorption most likely corresponds to desorption of the PAH from alumina, whereas the $30 \mathrm{~kJ} / \mathrm{mol}$ peak for phenanthrene may represent the phase transfer of a small amount of the bulk hydrocarbon in the supported sample. Exothermic oxidation processes are characterized by activation energies of 29,48 and $67 \mathrm{~kJ} / \mathrm{mol}$, and represent some specific oxidation pathways that are similar both for anthracene and $\mathrm{B} a \mathrm{P}$. Fresh samples of naphthalene and phenanthrene did not experience significant exothermic oxidation. The relative chemical activity of the four PAHs studied here was found to decrease from $\mathrm{B} a \mathrm{P}$ to anthracene, naphthalene and phenanthrene.

This pattern of chemical activity, derived from the intensities of the exothermic peaks, is also supported by the

Table 7. Temperatures and enthalpies of endothermic processes in pure and supported aromatic hydrocarbons at atmospheric pressure

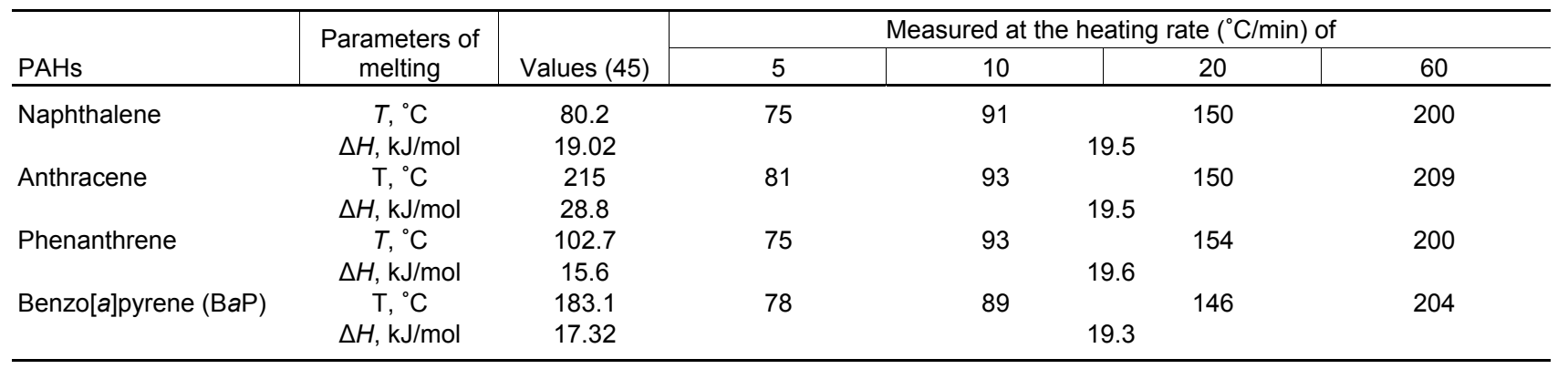



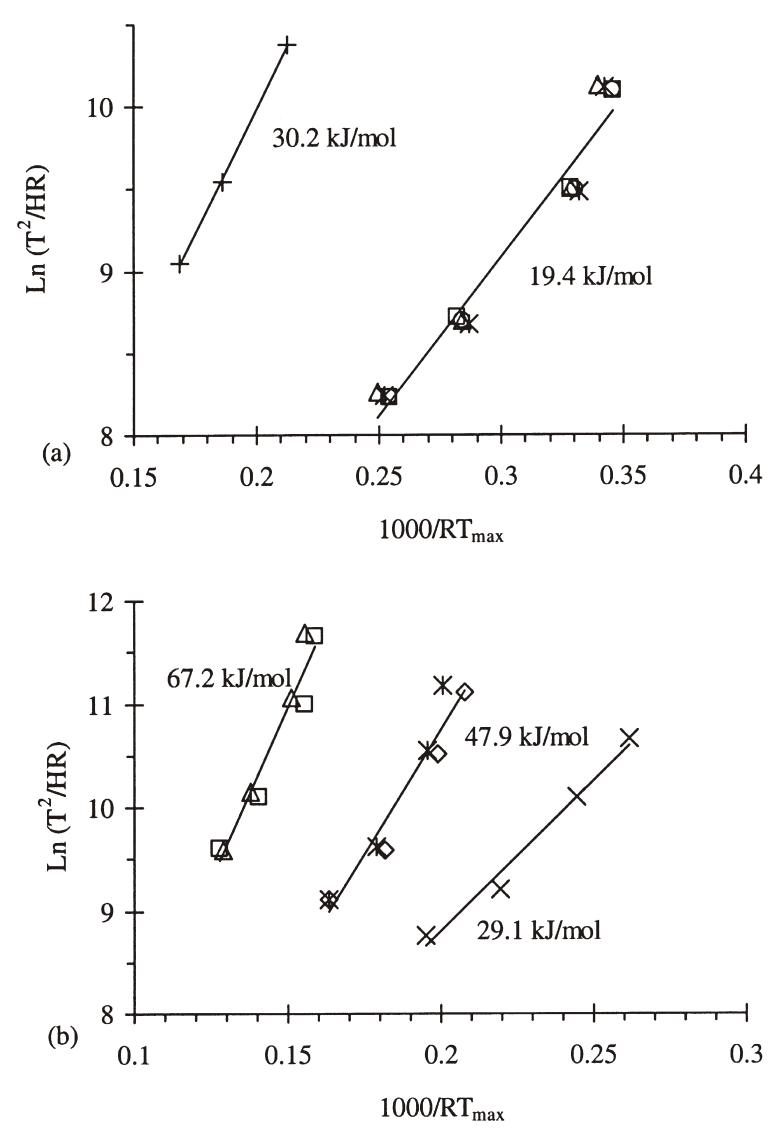

Figure 17. Endothermic (a) and exothermic (b) decomposition of PAH/alumina in $9 \% \mathrm{O}_{2}$ in He. PAHs were for endothermic processes: naphthalene $(0)$, phenanthrene $(\square)-1^{\text {st }}$ and $(+)-$ $2^{\text {nd }}$ peaks, anthracene $(\Delta)$ and $\operatorname{BaP}(*)$

for exothermic processes: anthracene $(x)-1^{\text {st }}$ and $(\diamond)-2^{\text {nd }}$ and $(\square)-3^{\text {rd }}$ peaks, BaP $\left({ }^{*}\right)-2^{\text {nd }}$ and $(\Delta)-3^{\text {rd }}$ peaks

yield of $\mathrm{CO}_{2}$ from the combustion reactor measured by mass-spectrometry. The total amounts of $\mathrm{CO}_{2}$, normalized to the naturally present internal standard argon were estimated to be $10,4,3$ and 1 for $\mathrm{B} a \mathrm{P}$, anthracene, naphthalene and phenanthrene, respectively. This same sequence of activity has been described in the literature $(43,44)$, where oxidation of PAHs was conducted catalytically in the gas phase and photochemically on alumina or silica support. BRUCKNER and BAERNS (43) showed that PAHs have much higher chemical activities when supported than when in water solutions. PAALME et al. (44) pointed out the similarity of the reaction pathways for different PAHs, an indication that the products of inner- and outer-ring oxidation are formed in primary steps while their decomposition occurs consecutively. These steps could be indicated by the exothermic peaks in Figure 16 for $\mathrm{B} a \mathrm{P}$ and anthracene. According to the literature, the oxidation processes, from low to high temperatures, may produce several intermediates: 9,10-anthraquinone, 2,3-naphthalic and pyromaleic anhydrides, and 1,4-anthraquinone from anthracene. The intermediate anhydrides readily produce carbon oxides.

Other PAHs produce the same classes of compounds; however, their particular products may differ. Thus, tetracarboxylic anhydride is formed from linear anthracene, but the bent phenanthrene does not form this product type (44). The greater stability of the phenanthrene structure observed in this work in comparison to anthracene is consistent with literature results $(45,46)$.

\section{CONCLUSIONS}

The formation and consumption of phenols found in cigarette smoke have been considered. As broadly defined sources of phenols, three groups of compounds have been investigated, i.e., polyhydroxybenzenes, aromatic hydrocarbons and carbohydrates, represented by lignins, pectin, glucose, phenol, hydroquinone, resorcinol, catechol, guaiacol, chlorogenic acid, caffeic acid, quinic acid, rutin, quercetin, naphthalene, anthracene, phenanthrene and benzo $[a]$ pyrene.

As supported by literature results, our results, highlighted in Table 8, can be explained by a model in which phenolrich 'tar' contains less stable isolated semiquinone and/or PAH-type molecules and a more stable quinone-hydroquinone-semiquinone $\left(\mathrm{Q}-\mathrm{QH}_{2}-\mathrm{HQ} \cdot\right)$ redox complex. One of the most abundant ingredients in plant fuels, lignin, showed different thermochemical properties, depending on its origin and method of extraction. This complicates interpretation of experiments with varied lignins.

Lignin's precursor, chlorogenic acid, was found to be an active source of phenols during combustion. All formed or added phenols provided radical-scavenging or radicalinitiating reactions, depending on the combustion conditions and the fuel type. Thus, the same phenolic compound rutin promoted low-temperature oxidation and less radical production for CS fuels, while suppressing oxidation and increasing radical concentrations for TB. Carbohydrates showed a limiting effect on $\mathrm{O}_{2}$ supply to the combustion zone. This limit on the $\mathrm{O}_{2}$ supply may affect both the temperature profiles and the probability of generation of radicals in a burning cigarette. Phenols were found to form from six-membered ring carbohydrates and quinic acid at relatively low temperatures. The quinone structure in this case may serve as an intermediate to the aromatic structure of phenol.

Individual phenols, if present in the fuel, were found to distill into smoke, polymerize or undergo oxidation. The more stable monohydroxybenzene mostly distills whereas the most reactive catechol polymerizes. The formation of semiquinone and quinone is facilitated when dihydroxybenzene is diluted by a combustible matrix, which prevents possible polymerization to PAHs. This dilution can be intra-molecular, when phenols are a part of a larger molecule, or a phenolic compound can be mixed with another matrix. Concentrated catechol structures, such as catechol, chlorogenic and caffeic acids, tend to polymerize to PAH, whereas their dilution led to an increase of the phenols in smoke. The possibility of distillation and re-adsorption of phenols on unburned fuel under the real cigarette conditions can also be considered.

The PAHs probably can be excluded as possible major precursors to phenols in smoke. Several endo- and exothermic processes, indicated and characterized in our experiments, comprised desorption and phase transfer of PAHs and their oxidation processes. The relative chemical activity was found to decrease from $\mathrm{B} a \mathrm{P}$ to anthracene, naphthalene and phenanthrene. The aged, supported PAHs showed evidence of progressing oxidation at room temperature, which results in the development of chemical activity. 


\begin{tabular}{|c|c|c|}
\hline Material & Observations & Suggested or explained by \\
\hline \multirow[t]{3}{*}{ Glucose } & $\begin{array}{l}\text { suppresses heat, more from TB } \\
\text { generates radicals in tar }\end{array}$ & $\begin{array}{l}\text { diffusion limitations to } \mathrm{O}_{2} \\
\text { via gas phase formyl; } \\
\text { no difference for TB - naturally has fructose }\end{array}$ \\
\hline & increases smolder temperature of CS & formation of low-molecular weight fuel \\
\hline & decrease smolder temperature of TB & diffusion limitations to $\mathrm{O}_{2}$ \\
\hline Pectin & $\begin{array}{l}\text { suppresses heat of combustion } \\
\text { additional combustion above } 700{ }^{\circ} \mathrm{C}\end{array}$ & $\begin{array}{l}\text { diffusion limitations to } \mathrm{O}_{2} \\
\text { formation of encapsulated fuel }\end{array}$ \\
\hline Chlorogenic acid & $\begin{array}{l}\text { inhibits TB combustion at } 340{ }^{\circ} \mathrm{C} \\
\text { intensifies combustion above } 450{ }^{\circ} \mathrm{C}\end{array}$ & $\begin{array}{l}\text { radical-scavenging by catechol group } \\
\text { more fuel remained in DSC chamber }\end{array}$ \\
\hline \multirow[t]{5}{*}{ Lignins } & three lignins - different reactivities & may not well represent the "tobacco" lignin \\
\hline & S: slow combustion below $350^{\circ} \mathrm{C}$ & dense, dry material out of hardwood \\
\hline & S: initial oxidation is very fast & accumulated oxygen, e.g., peroxy \\
\hline & A: fast combustion & alkali metal-catalyzed decomposition \\
\hline & $\mathrm{H}$ : active combustion, more products & lower molecular weight \\
\hline Quinic acid & $\begin{array}{l}\text { suppresses decomposition at } 300{ }^{\circ} \mathrm{C} \\
\text { increases the heat of combustion and phenols yield } \\
\text { at } 450{ }^{\circ} \mathrm{C}\end{array}$ & $\begin{array}{l}\text { increased yield of inhibitors, hydroquinone and catechol } \\
\text { formation of additional radicals; } \\
\text { propagating combustion }\end{array}$ \\
\hline Rutin & active inhibitor of radical-driven combustion & $\begin{array}{l}\text { catechol and resorcinol groups in molecule and in the } \\
\text { cleavage products }\end{array}$ \\
\hline Quercetin & $\begin{array}{l}\text { shows polymerization rather than cleavage } \\
\text { increase in combustion at } 470{ }^{\circ} \mathrm{C}\end{array}$ & $\begin{array}{l}\text { no carbohydrate moiety as in rutin } \\
\text { radicals are formed during higher temperature cleavage }\end{array}$ \\
\hline Caffeic acid & prone to polymerization, similarly to quercetin & $\begin{array}{l}\text { concentrated catechol structure; } \\
\text { forms low-temperature products when diluted }\end{array}$ \\
\hline Individual phenols & $\begin{array}{l}\text { vaporize or polymerize depending on combustion } \\
\text { conditions }\end{array}$ & $\begin{array}{l}\text { may scavenge radicals produced in combustion if transport } \\
\text { from firecone is slower than temperature increase }\end{array}$ \\
\hline Guaiacol & quite inert compound compared to other phenolics & methoxy group prevents formation of semiquinone radicals \\
\hline PAHs & $\begin{array}{l}\text { chemical activity decreases from BaP to anthracene, } \\
\text { naphthalene and phenanthrene }\end{array}$ & $\begin{array}{l}\text { PAHs may not be major contributors to the phenolics } \\
\text { reactions }\end{array}$ \\
\hline
\end{tabular}

\section{REFERENCES}

1. Schlotzhauer, W.S., M.E. Snook, O.T. Chortyk, and R.L. Wilson: Pyrolytic evaluation of low chlorogenic acid tobaccos in the formation of the tobacco smoke cocarcinogen catechol; J. Anal. Appl. Pyrolysis 22 (1992) 231-238.

2. Spears, A.W.: Quantitative determination of phenol in cigarette smoke; Anal. Chem. 35 (1963) 320-322.

3. Spears, A.W.: Selective filtration of volatile phenolic compounds from cigarette smoke; Tob. Sci. 7 (1963) 76-80.

4. Bell, J.H., A.O. Saunders, and A.W. Spears: The contribution of tobacco constituents to phenol yield of cigarettes; Tob. Sci. 10 (1966) 138-142.

5. Awad, A.B. and C.S. Fink: Phytosterols as anticancer dietary components: evidence and mechanism of action; J. Nutrition 130 (2000) 2127-2130.

6. Bassilakis, R., R.M. Carangelo, and M.A. Wojtowicz: TG-FTIR analysis of biomass pyrolysis; Fuel 80 (2001) 1765-1786.

7. Baliga, V.L., R. Sharma, D. Miser, T. McGrath, and M.R. Hajaligol: Physical characterization of pyrolyzed tobacco and tobacco components; J. Anal. Appl. Pyrolysis 66 (2003) 191-215.

8. Tamagnone, L., A. Merida, A. Parr, S. Mackay, F. A. Culianez-Macia, K. Roberts, and C. Martin: The ammyb308 and ammyb330 transcription factors from antirrhinum regulate phenylpropanoid and lignin biosynthesis in transgenic tobacco; Plant Cell 10 (1998) 135-154.
9. Sharma, R.K., J.B. Wooten, V.L. Baliga, and M.R. Hajaligol: Characterization of chars from biomassderived materials: pectin chars; Fuel 80 (2001) $1825-1836$.

10. Sharma, R.K. and M.R. Hajaligol: Effect of pyrolysis conditions on the formation of polycyclic hydrocarbons (PAHs) from polyphenolic compounds; J. Anal. Appl. Pyrolysis 66 (2003) 123-144.

11. Humphreys, J.M. and C. Chapple: Rewriting the lignin roadmap; Current Opinion in Plant Biology 5 (2002) 224-229.

12. Sharma, R.K., T.S. Fisher, and M.R. Hajaligol: Effect of reaction conditions on pyrolysis of chlorogenic acid; J. Anal. Appl. Res. 62 (2002) 281-296.

13. Bokelman, G.H. and W.S. Rayan: Analysis of bright and burley tobacco laminae and stems; Beitr. Tabakforsch. Int. 13 (1985) 29-36.

14. Micard, V., J.H. Grabber, J. Ralph, C.M.G.C. Renard and J.F. Thibault: Dehydrodiferulic acids from sugarbeet pulp; Phytochemistry 44 (1997) 1365-1368.

15. LeVan, S.L.: Thermal properties; in: The Concise Encyclopedia of Wood \& Wood-Based Materials, $1^{\text {st }}$ edition, edited by A.P. Schniewind, Pergamon Press, Elmsford, NY, pp. 271-273.

16. Ralph J., C. Lapierre, J.M. Marita, H. Kim, F. Lu, R.D. Hat, S. Ralph, C. Chapple, R. Franke, M.R. Hemm, J.Van Doorsselaere, R.R. Sedero, D.M. O'Malley, J.T. Scott, J.J.MacKay, N. Yahiaoui, A.M. Boudet, M. Pean, G. Pilate, L. Jouanin, and W. Boerjan: Elucidation of new structures in lignins of cad- and comt-deficient plants by NMR; Phytochemistry 57 (2001) 993-1003 . 
17. Andersen, R.A. and M.J. Kasperbauer: Effects of nearultraviolet radiation and temperature on soluble phenols in Nicotiana tabacum; Phytochemistry 10 (1971) 1229-1232.

18. Tamagnone, L., A. Merida, N. Stacey, K. Plaskitt, A. Parr, C. Chang, D. Lunn, J.M. Dow, K. Roberts, and C. Martin: Inhibition of phenolic acid metabolism results in precocious cell death and altered cell morphology in leaves of transgenic tobacco plants; Plant Cell 10 (1998) 1801-1816.

19. Chabannes, M., A. Barakate, C. Lapierre, J.M. Marita, J. Ralph, M. Pean, S. Danoun, C. Halpin, J. Gima-Pettenati, and A.M. Boudet: Strong decrease in lignin content without significant alteration of plant development is induced by simultaneous down-regulation of cinnamoyl coa reductase (CCR) and cinnamyl alcohol dehydrogenase (CAD) in tobacco plants; Plant J. 28 (2001) 257-270.

20. Scheijen, M.A., J.J. Boon, W. Hass, and V. Heemann: Characterization of tobacco lignin preparations by curiepoint pyrolysis-mass spectrometry and curie-point pyrolysis-high-resolution gas chromatography/mass spectrometry; J. Anal. Appl. Res. 15 (1989) 97-120.

21. Faix, O., J. Bremer, D. Meier, I. Fortmann, M.A. Scheijen, J.J. Boon, W. Hass and V. Heemann: Characterization of tobacco lignin by analytical pyrolysis and Fourier transform-infrared spectroscopy; J. Anal. Appl. Res. 22 (1992) 239-259.

22. Gamborg, O.L.: Aromatic metabolism in plants. IV. The interconversion of shikimic acid and quinic acid by enzymes from plant cell cultures; Phytochemistry 6 (1967) 1067-1073.

23. Begum, L., J.M. Box, M.G.B. Drew, M.L. Harwood, J.L. Humphreys, J.D. Lowes, G.A. Morris, P.M. Redin, F.M. Walker, and R.C. Whitehead: Difluorinated analogues of shikimic acid; Tetrahedron 59 (2003) 4827-4841.

24. Wornat, M.J., E.B. Ledesma, and N.D. Marsh: Polycyclic aromatic hydrocarbons from the pyrolysis of catechol (ortho-dichlorobenzene), a model fuel representative of entities in tobacco, coal, and lignin; Fuel 80 (2001) 1711-1726.

25. Shin, E.-J., D.E. Miser, W.G. Chan, and M.R. Hajaligol: Catalytic cracking of catechols and hydroquinones in the presence of nano-particle iron oxide; Appl. Catalysis B: Environmental 61 (2005) 79-89.

26. Lee, R.F.: Photo-oxidation and photo-toxicity of crude and refined oils; Spill Science \& Technology Bulletin 8 (2003) 157-162.

27. McGrath, T., R. Sharma, and M.R. Hajaligol: An experimental investigation of polyaromatic hydrocarbons (PAH) from pyrolysis of biomass materials; Fuel 80 (2001) 1787-1797.

28. Babushok, V.I. and W. Tsang: Gas-phase mechanism for dioxin formation; Chemosphere 51 (2003) 1023-1029.

29. Gullett, B.K. and A. Touati: PCDD/F emissions from forest fire simulations; Chemosphere 37 (2003) 803-813.

30. Gullett, B.K. and K. Raghunathan: Observations on the effect of process parameters on dioxin/furan yield in municipal waste and coal systems; Chemosphere 34 (1997) 1027-1032.

31. W.A. Pryor: Reactions of radicals. A comparison of peroxides and disulfides; Tetrahedron Letters 18 (1963) 1201-1204.
32. Pryor, W.A., D.F. Church, M.D. Evans, W.Y. Rice, and J.R. Hayes: A comparison of the free radical chemistry of tobacco-burning cigarettes and cigarettes that only heat tobacco; Free Radical Biology \& Medicine 8 (1990) 275-279.

33. Morsy, M.A. and M.M. Khaled: Novel EPR characterization of the antioxidant activity of tea leaves; Spectrochimica Acta: Part A, 58 (2002) 1271-1277.

34. Pryor, W.A., B.J. Hales, P.I. Premovic, and D.F. Church: The radicals in cigarette tar: their nature and suggested physiological implications; Science 220 (1983) 425-427.

35. Morsy, M.A. and M.M. Khaled: Novel EPR characterization of the antioxidant activity of tea leaves; J. Agric. Food Chem. 49 (2001) 683-686.

36. Baum, S.L., I.G. Anderson, R.R. Baker, D.M. Murphy, and C.C. Rowlands: Electron spin resonance and spin trap investigation of free radicals in cigarette smoke: development of a quantification procedure; Analytica Chimica Acta 481 (2003) 1-13.

37. Baker, R.R.: Temperature variations within a cigarette combustion coal during the smoking cycle; High. Temp. Sci. 7 (1975) 236-247.

38. Dyakonov, A.J., D.A. Grider, and A.M. Ihrig: Smolder of cellulosic fabrics; J. Fire Sciences. 16 (1998) 297-322, (1999) 71-85, 17 (1999) 175-187, and 17 (1999) 438-458.

39. Pryor, W.A.: Biological effects of cigarette smoke, wood smoke, and the smoke from plastics: the use of electron spin resonance; Free Radical Biol. Med. 13 (1992) 659-676.

40. Demirbas, A.; Partly chemical analysis of liquid fraction of flash pyrolysis products from biomass in the presence of sodium carbonate; Energy Conversion and Management 43 (2002) 1801-1809.

41. Handbook of Chemistry and Physics, edited by D.R. Lide, $74^{\text {th }}$ Edition, 1993-1994.

42. Dupont, L., A. El Bakali, J.F. Pauwels, I. Da Cocta, P. Meunier, and $\mathrm{H}$. Richter: Investigation of stoichiometric methane/air/benzene $(1.5 \%)$ and methane/air low pressure flames; Combust. Flame 135 (2003) 171-183.

43. Bruckner, A. and M. Baerns: Selective gas-phase oxidation of polycyclic aromatic hydrocarbons on vanadium oxide-based catalysts; Appl. Catalysis A: General 157 (1997) 311-334.

44. Paalme, L., N. Irha, E. Urbas, A. Tsyban, and U. Kirso: Model studies of photochemical oxidation of carcinogenic polyaromatic hydrocarbons; Marine Chemistry 30 (1990) 105-111.

45. Wade, L.G.: Organic Chemistry, Prentice Hall, Inc., NJ 1991, p. 696; NIST Chemistry Webbook, webbook.nist.gov

46. Brown, G.S., L.L. Barton, and B.M. Thomson: Permanganate oxidation of sorbed polycyclic aromatic hydrocarbons; Waste Management 23 (2003) 737-740.

Corresponding author:

Alexander J. Dyakonov

A. W. Spears Research Center,

Lorillard Tobacco Co.,

420 English St.,

Greensboro NC 27420, USA

E-mail:adyakonov@lortobco.com 